\title{
Offshoring of Services: A Review of the Literature and Organizing Framework
}

\author{
Niccolò Pisani ${ }^{1} \cdot$ Joan Enric Ricart ${ }^{2}$
}

Received: 22 April 2014/Revised: 18 August 2015/Accepted: 26 August 2015/

Published online: 20 November 2015

(C) The Author(s) 2015. This article is published with open access at Springerlink.com

\begin{abstract}
Offshoring of services (OS), commonly defined as the international relocation of service activities that companies previously performed in their home country, has emerged as a relevant phenomenon in international business (IB). Over the past two decades, OS has grown rapidly in the global economy and it has increasingly attracted IB scholars' attention. In this study, we systematically review the literature to map and assess the body of IB research focused on the OS phenomenon. To achieve our goal, we identify and analyze a total of 79 studies that appeared from 1990 to 2014 in a select group of 14 journals that are widely considered leading publishers of IB research. This review seeks to make a threefold contribution to the IB discipline. First, it provides an in-depth analysis of the OS literature through a synthesis of the theoretical perspectives adopted and an assessment of the empirical findings obtained. Second, it offers an organizing framework that contributes to a more nuanced understanding of the OS phenomenon. Third, it identifies emerging topics on the OS frontier and suggests potential avenues for future research.
\end{abstract}

Keywords Offshoring of services - Services relocation - Offshore outsourcing · Globally distributed work $\cdot$ Systematic review

Niccolò Pisani

n.pisani@uva.nl

Joan Enric Ricart

JERicart@iese.edu

1 Amsterdam Business School, University of Amsterdam, Amsterdam, The Netherlands

2 Carl Schroeder Chair of Strategic Management, IESE Business School, University of Navarra, Barcelona, Spain 


\section{Introduction}

Offshoring of services (OS) represents a remarkable economic and social phenomenon in the international business (IB) scenario of the past two decades. OS can be defined as "the transnational relocation or dispersion of service activities" that companies previously performed in their home country, including captive (internal) and outsourced (external) delivery modes (Doh et al. 2009, p. 927). ${ }^{1}$ Services include a wide spectrum of activities, ranging from software development to medical transcription. Service activities have been characterized traditionally by four essential qualities: intangibility, heterogeneity in outputs, perishability, and inseparability of production and consumption (Bessom and Jackson 1975; Di Gregorio et al. 2009; Erramilli and Rao 1990). The impossibility of separating the production and consumption of a service has obviously precluded the geographic relocation of its production away from the consumer. Recent advances in information and communications technology (ICT) and the emergence of a global workforce have helped loosen this constraint, enabling companies to relocate service activities formerly considered nonoffshorable to foreign locations, where they can be performed more efficiently and coordinated in a global system (Apte and Mason 1995; Bunyaratavej et al. 2007; Hahn et al. 2011; Murray and Kotabe 1999; Tambe and Hitt 2012).

Over the past two decades the OS phenomenon has grown substantially (NASSCOM and McKinsey 2009; UNCTAD 2004) and attracted the increased attention of political spheres, practitioners, and the popular press (Booth 2013; Bunyaratavej et al. 2011; Dossani and Kenney 2007). IB scholars have progressively investigated OS-related topics, widely reputed to be at the frontier of IB thinking (Doh et al. 2009; Luo et al. 2012; Manning et al. 2008; Parkhe 2007). Published studies have highlighted that OS represents a new type of internationalization, which interests a variety of service activities (Javalgi et al. 2009; Lewin et al. 2009; Lewin and Peeters 2006; Nieto and Rodríguez 2011) and implies considerable repercussions at the individual, firm, and country levels (Bunyaratavej et al. 2008; Contractor et al. 2010; Kumar et al. 2009; Liesch et al. 2012; Manning et al. 2010). Scholars have also suggested that OS generates important challenges to established IB theories, raising a host of stimulating questions and offering a fertile setting for research (Bunyaratavej et al. 2011; Doh 2005; Doh et al. 2009; Kenney et al. 2009). As a result, the OS literature has begun to develop within the broader IB field.

While reviews and conceptual articles related to the general offshoring phenomenon have appeared in the recent past, a systematic review specifically focused on the OS literature is still lacking. IB scholars have dedicated special issues to the offshoring topic (Contractor et al. 2010; Jensen et al. 2013; Kenney et al. 2009; Kotabe and Mudambi 2009; Lewin and Volberda 2011; Parkhe 2007) and published insightful reviews on the offshoring of value chain activities (Schmeisser 2013) and the particular governance mode of offshore outsourcing

\footnotetext{
${ }^{1}$ See also Bunyaratavej et al. (2011), Doh (2005), Kenney et al. (2009), and Manning et al. (2008) for comparable and consistent definitions of OS.
} 
(Hätönen and Eriksson 2009). Others have limited the scope of their reviews to particular aspects of the offshoring phenomenon and grounded their works in different fields, focusing on the relocation of knowledge-intensive, higher valueadding tasks, business functions, processes, or IT-related activities (Javalgi et al. 2009; Lacity et al. 2010, 2011; Rilla and Squicciarini 2011; Youngdahl and Ramaswamy 2008). Only Bunyaratavej et al. (2011) limited the scope of their review to OS but they investigated articles that appeared before 2010, restricted their analysis to specific aspects of the received literature, and provided a relatively narrative appraisal of this body of research.

The purpose of our study is to fill this gap by offering a systematic review of the IB literature focused on the OS phenomenon. To do so, we undertake a rigorous review process that leads to the identification and analysis of a total of 79 OSrelated studies that appeared from 1990 to 2014 in a select group of 14 journals widely considered to be leading publishers of IB research. Our work updates and expands on earlier reviews by providing a historical assessment of the theoretical lenses adopted in OS research, an analytical appraisal of the key attributes of this literature, and a synthesis of the empirical findings obtained in OS-related studies published up to December 2014. Moreover, we build upon the conceptual work of Schmeisser (2013) on the broader offshoring of value chain activities to offer an organizing framework that helps to contextualize OS and appreciate its peculiarities.

We acknowledge that the OS phenomenon has important implications for other fields beyond IB and is the object of substantial research in other literatures as well, such as information systems (IS) and operations management (OM). In an effort to show how the IB field can benefit by working more closely with other related fields, our study also contains an ad hoc review of OS-related studies that appeared from 1990 to 2014 in three leading IS journals. Aside from this additional analysis related to the IS literature, our review deliberately focuses only on the IB field, seeking to contribute to the IB discipline in three ways: first, it offers an analytical assessment of the key attributes of the OS literature and provides a systematic analysis of this body of research through a synthesis of theoretical perspectives adopted and empirical findings obtained; second, it offers a framework that contributes to a more nuanced understanding of the OS phenomenon and helps to contextualize the features that are unique to the OS scenario within the broader IB field; third, it identifies emerging topics and suggests promising avenues for future research.

The remainder of the article is organized into five sections. In the following section, we introduce the methodology adopted in the review process. In the third section, we provide a descriptive analysis of the articles selected and an assessment of the main theoretical lenses used. The fourth section contains a thematic analysis of the OS literature where we synthesize the articles reviewed and offer insights on the findings obtained. In the fifth section, we elaborate an organizing framework for understanding OS and its mechanisms, discuss emerging topics on the OS frontier, and identify promising avenues for future research. The sixth and last section contains our concluding remarks. 


\section{Methodology}

To map and review the body of IB research on the OS phenomenon we applied the methodology delineated by Tranfield et al. (2003), which was employed recently by Schmeisser (2013). In the work of Tranfield et al. (2003), management reviews comprise three fundamental stages: (1) a thorough a priori planning of the review that identifies its aim and delineates its subject area, (2) a systematic completion of the review process conducted via a comprehensive, unbiased search whose details are conveyed in sufficient detail to guarantee its replicability, and (3) an exhaustive dissemination of results. In the introduction we tackled the first stage, discussing the underlying motivation of this review and defining its subject area. In this section, we concentrate on the second stage and describe the search criteria used to identify and select relevant studies. In the following section we will focus on the third stage, assessing the articles reviewed and providing insights on the findings obtained.

\subsection{Selection of Journals}

We focused on publications in peer-reviewed academic journals, excluding other publication outlets such as books, monographs, or conference proceedings. We selected journals that are widely acknowledged as the leading publishers of IB research in order to identify all high-quality scholarly investigations on OS. Thus, we selected 14 journals-five leading journals focused exclusively on IB topics and nine top-ranked journals within the broader realm of management. The inclusion of this second set of journals was necessary as the existing research corroborates the view that a significant portion of high-quality IB research appears in these outlets as well (Inkpen 2001; Pisani 2009; Schmeisser 2013). To maintain a clear focus on the IB field, we excluded journals from other fields (e.g., marketing) whose inclusion would have diverted the scope of our review significantly.

For the first group of journals, our selection was grounded in previous reviews (Chan et al. 2006; Ellis and Zhan 2011; Kothari and Lahiri 2012; Lahiri and Kumar 2012; Schmeisser 2013), from which we identified the following outlets: Journal of International Business Studies, Management International Review, Journal of World Business, International Business Review, and Journal of International Management. To select the second group of outlets, we based our choice on a highly established list of management journals (Gomez-Mejia and Balkin 1992; Judge et al. 2007; Pisani 2009; Podsakoff et al. 2005; Schmeisser 2013; Werner 2002) and selected: Academy of Management Journal, Academy of Management Review, Strategic Management Journal, Journal of Management, Journal of Management Studies, Management Science, Organization Science, Organization Studies, and Administrative Science Quarterly.

\subsection{Selection of Articles}

We used Thomson Reuters Web of Knowledge and EBSCOhost Business Source Premier databases to retrieve articles from the 14 journals selected. Since the 
existing research indicates that the first OS relocations took place in the early $1990 \mathrm{~s}$ (Kotabe and Mudambi 2009), we used January 1990 as the cutoff point to guarantee the inclusion of all relevant articles focused on the OS topic. Given that the article search was performed in May 2015, we limited the end date of the search parameters to December 2014 so as to include 12 months for each of the years considered. Between January 1990 and December 2014, the 14 selected journals published a total of 17,620 articles, excluding book reviews. As regularly done in IB reviews (Aykol et al. 2013; Schmeisser 2013), we performed a keyword search to look for articles that referred to OS in the title, abstract, and/or keywords provided by the authors. To do so, we ran two different keyword search algorithms on the entirety of articles using standard Boolean operators and then consolidated the results from both searches.

In the first search, we looked for articles that directly referred to offshoring or made reference via the use of synonyms to the international sourcing of activities. This first search was purposefully broader in nature to guarantee that all articles that potentially focused on the OS topic could be identified (e.g., studies using broader terms such as business process offshoring). The second search was more detailed and looked for articles that made explicit reference to the international sourcing of service activities. ${ }^{2}$ The consolidated search resulted in the identification of 332 articles. We manually revised the titles and abstracts of all articles and excluded those that did not focus on the OS topic - that is, articles that did not explicitly address the offshoring of service activities (e.g., studies on the international sourcing of manufacturing activities) or lacked the international aspect of OS (e.g., studies on the domestic relocation of services).

In this screening process we also encountered studies that focused on the offshoring phenomenon at large or referred to the international relocation of undefined business processes. In such cases, we included only articles that, while remaining at a broader level of analysis, informed the scholarly debate on the OS phenomenon or discussed the peculiarities related to the offshoring of service activities to a meaningful extent. When in doubt, we read the entire article to determine whether its inclusion in the OS literature would be pertinent. This process led to the final selection of 79 articles that we read and categorized according to journal, main topic studied, theoretical lens adopted, level of analysis, focus on captive and/or outsourcing governance modes, adoption of a headquarters/client and/or subsidiary/provider perspective, as well as the home and host regions selected for the study. While an analysis of the methods used in the 79 articles was not a primary objective of this review, we still distinguished among conceptual, empirical, and case-based studies so as to inform the reader about the general tendency observed in the OS literature as well as the specific subgroups identified.

We complemented this IB review with an ad hoc review of the IS literature to appraise the different angle this literature prioritizes in relation to the OS topic. In

\footnotetext{
2 The two keyword search algorithms performed were: (1) "offshor*" OR "outsourc*" OR ("regional" OR "global" OR "international" OR "multinational") AND "sourcing"; (2) ("regional" OR "global" OR "international" OR "multinational") AND ("sourc*" OR "reloc*" OR "re-loc*" OR "distribution" $O R$ "configuration" $O R$ "dispersion") AND "servic*". The asterisk was used to allow for changes at the end of the corresponding term included in the search algorithm.
} 
order to give a brief yet rigorous overview of IS research focused on OS, we replicated the same search done for the IB field in three leading IS journals: MIS Quarterly, Information Systems Review, and Information Systems Journal. The keyword search encompassing the same period (1990-2014) resulted in the identification of 49 articles, 18 of which focused on the OS topic. Accordingly, we read and categorized them using the same criteria adopted for the IB articles.

\section{Preliminary Analysis}

In this section, we report a descriptive analysis of the articles selected. As also advocated by Tranfield et al. (2003), such a descriptive account allows for a clearer assessment of the literature reviewed and is an ideal complement to the thematic analysis that will follow. This section also contains an examination of the main theoretical lenses adopted by scholars to frame the discourse on the OS phenomenon and conceptualize it within the broader IB field, providing insights into the peculiarities of this body of research.

\subsection{Descriptive Analysis}

Table 1 sets out the key attributes of the articles reviewed. Our decision to use January 1990 as the cutoff point ensured the inclusion of all IB articles focused on OS as the first study appeared in 1995. Accordingly, Apte and Mason's 1995 article "Global disaggregation of information-intensive services" represents the foundational work in the OS literature. The appearance of OS-related studies has grown exponentially over time as illustrated in Fig. 1. Our analysis also confirms that most conceptual studies were published between 1995 and 2009 while empirical investigations primarily appeared from 2009, possibly because of the initial difficulties to gather empirical data on OS. The journals exclusively dedicated to IB topics published the vast majority (almost $80 \%$ ) of all OS articles. The extent to which mainstream management journals cover the OS topic seems limited by comparison, given that four of the top nine journals within the broader management field did not publish a single article on OS from 1990 to 2014.

OS is fundamentally related to a firm-level decision regarding the relocation of selected services abroad (Apte and Mason 1995; Doh et al. 2009; Murray and Kotabe 1999), so it is not surprising that researchers tend to adopt a firm-level approach to investigating OS. That said, the regular adoption of multiple levels of analysis underscores the importance of studying OS using a multilevel approach, which is particularly relevant when it comes to IB research (Buckley and Lessard 2005). Regarding the governance mode of OS implementations, we find that outsourcing is the predominant mode investigated, mostly via empirical works (Kedia and Mukherjee 2009; Mason and Leek 2008; Narayanan et al. 2009; Parkhe 2007; Soderberg et al. 2013). Captive OS has been the exclusive subject of 10 studies (e.g., Bunyaratavej et al. 2007; Demirbag et al. 2012; Sidhu and Volberda 2011). Additional ad hoc analysis shows that most of these works were published between 2010 and 2014. Increased attention to the captive mode of governance 
Table 1 Key attributes of the OS literature

\begin{tabular}{|c|c|c|c|c|}
\hline \multirow[t]{2}{*}{ Key attributes } & \multirow[t]{2}{*}{ Frequencies $(\%)$} & \multicolumn{3}{|l|}{ Methodology } \\
\hline & & Conceptual & Empirical & Case study \\
\hline \multicolumn{5}{|l|}{ Publishing journal } \\
\hline Journal of International Management & $24(30 \%)$ & $11(50 \%)$ & $6(17 \%)$ & $7(32 \%)$ \\
\hline Journal of International Business Studies & $11(14 \%)$ & $1(5 \%)$ & $7(20 \%)$ & $3(14 \%)$ \\
\hline Journal of World Business & $10(13 \%)$ & $1(5 \%)$ & $3(9 \%)$ & $6(27 \%)$ \\
\hline Journal of Management Studies & $8(10 \%)$ & $4(18 \%)$ & $2(6 \%)$ & $2(9 \%)$ \\
\hline Management International Review & $7(9 \%)$ & $3(14 \%)$ & $4(11 \%)$ & $0(0 \%)$ \\
\hline International Business Review & $7(9 \%)$ & $1(5 \%)$ & $4(11 \%)$ & $2(9 \%)$ \\
\hline Strategic Management Journal & $5(6 \%)$ & $0(0 \%)$ & $5(14 \%)$ & $0(0 \%)$ \\
\hline Management Science & $5(6 \%)$ & $1(5 \%)$ & $4(11 \%)$ & $0(0 \%)$ \\
\hline Organization Science & $1(1 \%)$ & $0(0 \%)$ & $0(0 \%)$ & $1(5 \%)$ \\
\hline Organization Studies & $1(1 \%)$ & $0(0 \%)$ & $0(0 \%)$ & $1(5 \%)$ \\
\hline Total & $79(100 \%)$ & $22(100 \%)$ & $35(100 \%)$ & $22(100 \%)$ \\
\hline \multicolumn{5}{|l|}{ Level of analysis } \\
\hline Country & $5(6 \%)$ & $2(9 \%)$ & $2(6 \%)$ & $1(5 \%)$ \\
\hline Industry & $3(4 \%)$ & $0(0 \%)$ & $2(6 \%)$ & $1(5 \%)$ \\
\hline Firm & $35(44 \%)$ & $8(36 \%)$ & $16(46 \%)$ & $11(50 \%)$ \\
\hline Task/Implementation & $11(14 \%)$ & $0(0 \%)$ & $10(29 \%)$ & $1(5 \%)$ \\
\hline Individual/Team & $6(8 \%)$ & $0(0 \%)$ & $2(6 \%)$ & $4(18 \%)$ \\
\hline Multiple & $19(24 \%)$ & $12(55 \%)$ & $3(9 \%)$ & $4(18 \%)$ \\
\hline Total & $79(100 \%)$ & $22(100 \%)$ & $35(100 \%)$ & $22(100 \%)$ \\
\hline \multicolumn{5}{|l|}{ Governance mode } \\
\hline Only outsource offshoring & $26(33 \%)$ & $7(32 \%)$ & $11(31 \%)$ & $8(36 \%)$ \\
\hline Only captive offshoring & $10(13 \%)$ & $0(0 \%)$ & $8(23 \%)$ & $2(9 \%)$ \\
\hline Both captive and outsource offshoring & $43(54 \%)$ & $15(68 \%)$ & $16(46 \%)$ & $12(55 \%)$ \\
\hline Total & $79(100 \%)$ & $22(100 \%)$ & $35(100 \%)$ & $22(100 \%)$ \\
\hline
\end{tabular}

Percentages rounded

follows the progression observed in OS operations. At first, firms primarily entered into OS ventures through contractual agreements with offshore providers offering basic services, while more recently captive solutions have been used increasingly to organize complex OS relocations (Lewin et al. 2009; Nieto and Rodríguez 2011).

Table 2 shows the perspectives generally adopted for investigating OS in empirical and case studies. From a geographic standpoint, most OS practices examined are initiated by Western multinationals located in the United States or Western Europe looking to shift service activities to developing countries, predominantly in Asia (Demirbag et al. 2012; Jensen 2012; Lahiri et al. 2012; Luo et al. 2012). Our analysis indicates that, in the past five years, IB scholars have extended their geographic coverage to investigate the implementation of OS by multinationals headquartered outside Western Europe and the United States 


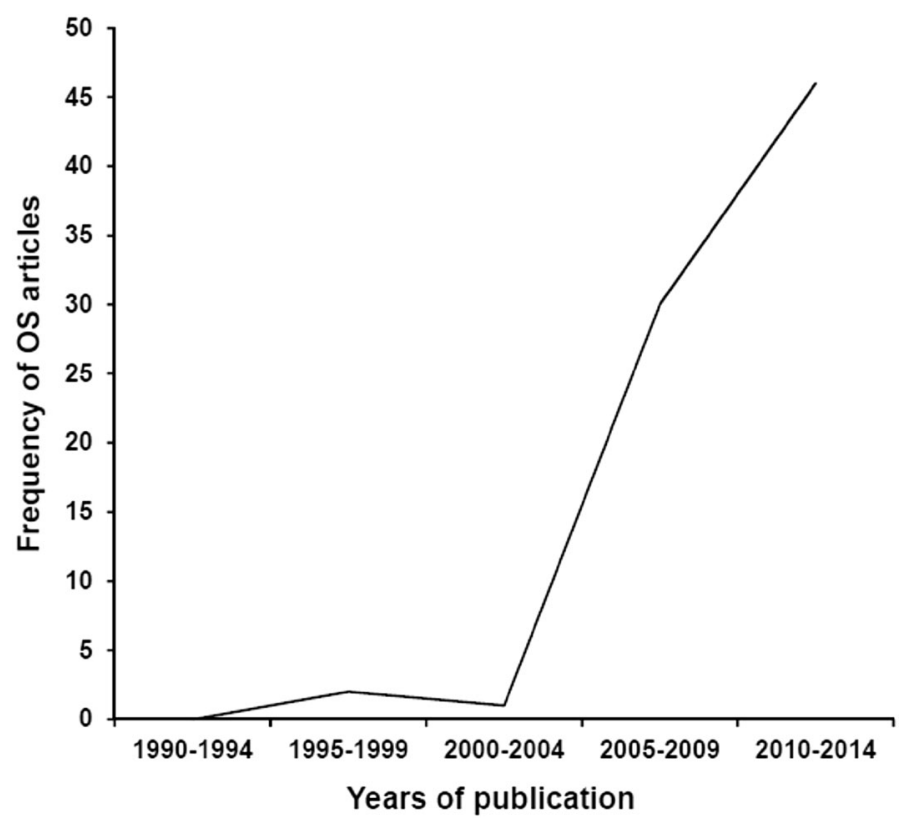

Fig. 1 The rise of the OS literature

(Jandhyala 2013; Vivek et al. 2009; Zaheer et al. 2009). While Asia as a recipient of OS relocations has continued to attract most of the scholarly work, the literature also contains several studies that examine OS practices involving subsidiaries and providers located outside this region (Demirbag and Glaister 2010; Jensen and Petersen 2013). Thus, our results suggest that scholars have demonstrated an increased awareness of the global redistribution of service activities beyond the classic migration from developed countries to lower-cost areas in Asia.

In terms of the perspective adopted for investigating OS, our findings illustrate that most researchers have taken the headquarters/client perspective, mainly addressing the OS phenomenon from the viewpoint of Western multinationals (Hahn et al. 2011; Hätönen 2009). Given that Western firms have traditionally represented the primary initiators of OS practices and continue to be their driving force, such a bias was predictable. That said, our findings also indicate that in 2009 the subsidiary/provider perspective was used for the first time as a stand-alone perspective (Kshetri and Dholakia 2009; Lahiri and Kedia 2009; Narayanan et al. 2009) and has been regularly adopted since then (Luo et al. 2012; Manning et al. 2011; Pereira and Anderson 2012; Raman et al. 2013). This tendency represents an innovative feature of the OS literature, one that deserves careful consideration. It documents scholars' growing attention paid to the challenges and related opportunities offered to the actual recipients of OS relocations. It also confirms that the providers of offshore services are turning into increasingly relevant actors in the OS scenario and their perspective is becoming crucial for understanding the global implications of the OS phenomenon. 


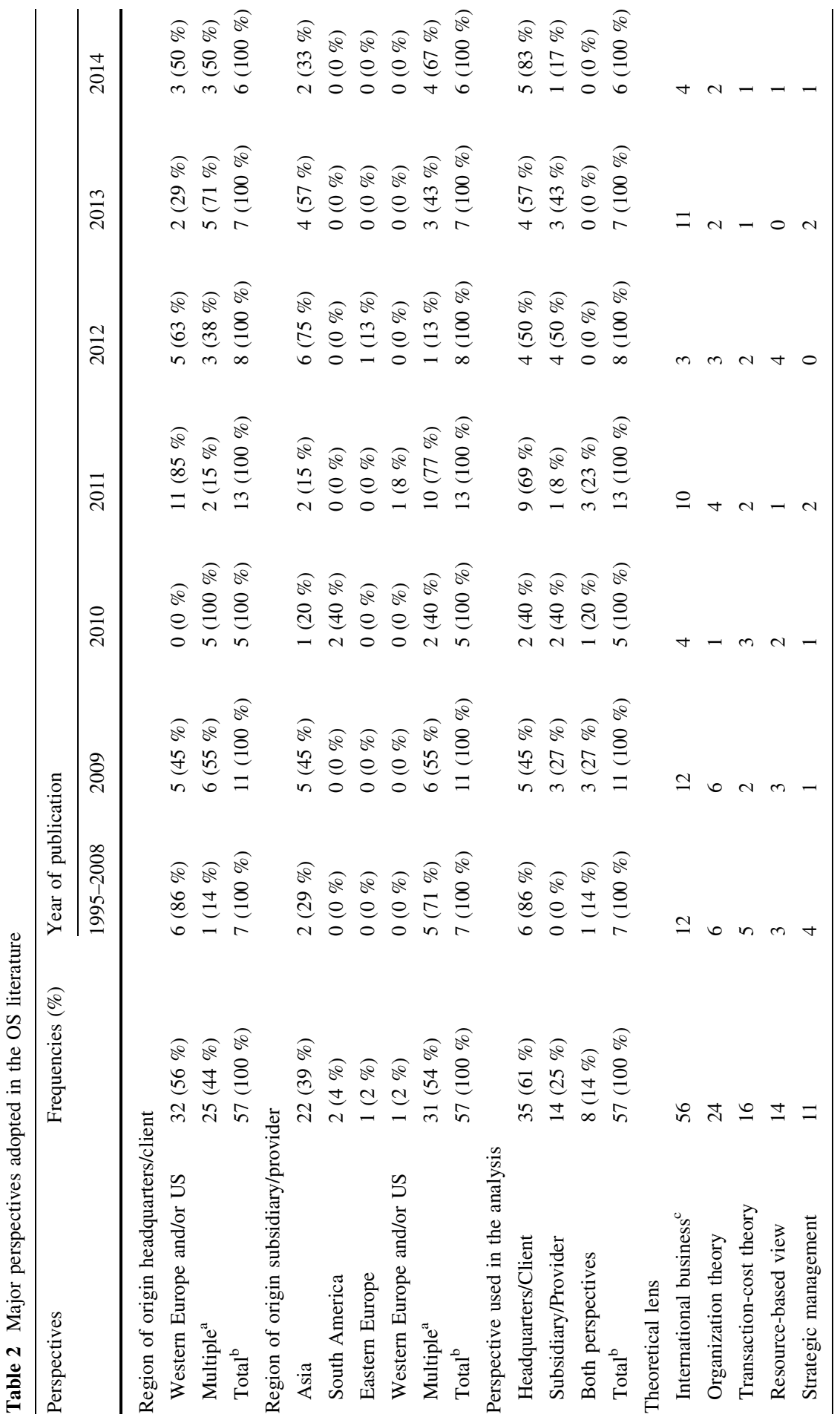




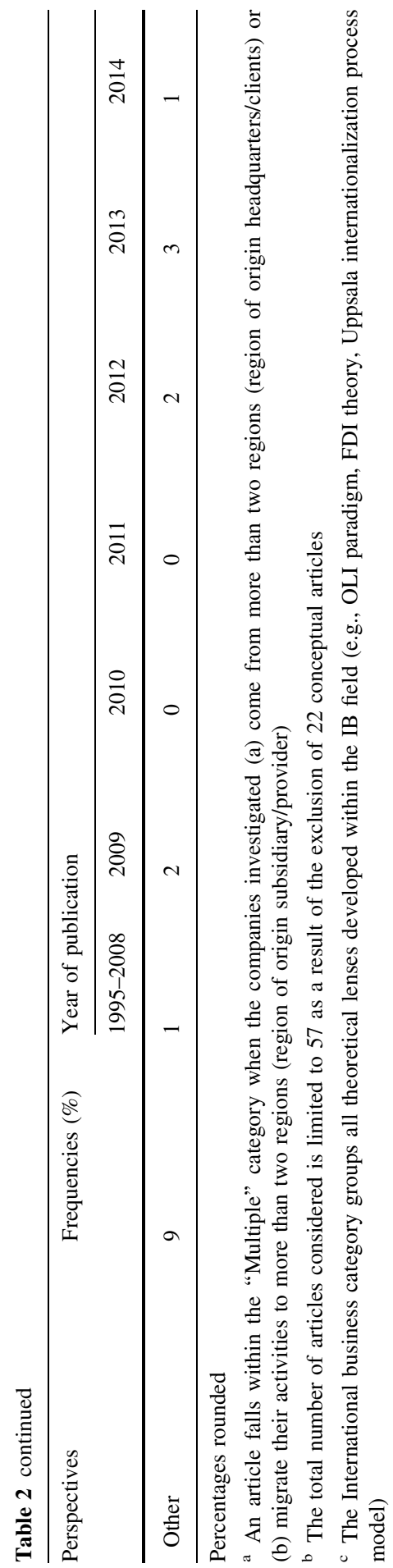




\subsection{Theoretical Lenses}

From the start, a vibrant debate has taken place about the theoretical implications of OS (Doh 2005). Our findings confirm that IB scholars have adopted distinct perspectives, used multiple levels of analysis, and embraced different theoretical lenses, often simultaneously, to frame their discourse on OS. The purpose of this subsection is to provide a synthesis and assessment of the main theoretical approaches embraced by OS research.

Following the markedly international connotation of the OS phenomenon, scholars have focused regularly on IB theories to investigate its peculiar aspects. The OLI paradigm (Dunning 2000) has been used to a large extent to address the choice of OS locations (Bunyaratavej et al. 2008; Demirbag and Glaister 2010; Graf and Mudambi 2005; Kedia and Mukherjee 2009). Scholars have also employed an economic geography perspective to study the distribution of OS activities (Jensen and Pedersen 2011), and have drawn on the internationalization process literature to investigate OS performance (Hutzschenreuter et al. 2011b) as well as locational aspects (Hahn et al. 2011; Hätönen 2009). International entrepreneurship literature has been used to frame the discussion of the OS effect on firm performance in the context of small and medium enterprises (Di Gregorio et al. 2009), while international business network theory has been applied to investigate the evolution and final outcome of OS processes (Jensen 2012). FDI theory on motives for investing abroad has been used to examine how recent progress in ICT has altered the drivers for expanding across borders (Nachum and Zaheer 2005; Zaheer and Manrakhan 2001).

The transaction-cost economics (TCE) perspective (Williamson 1981) has also been employed extensively to address the OS phenomenon (Murray and Kotabe 1999). This approach is widely used to investigate optimal disaggregation levels, "to understand the potential in fine-slicing, mobilizing and re-integrating specific value chain activities" (Mudambi and Venzin 2010, p. 1513). Scholars have adopted the TCE perspective to investigate the OS governance mode decision and the stability of the offshore-outsource relationship over time (Manning et al. 2011; Vivek et al. 2009). Especially in the early phases of the OS literature, TCE has been used to model the decision to restrict OS operations to relatively lower-level service activities. In particular, Murray and Kotabe (1999) focus on service firms and build on the distinction between core and supplementary services, proposing a modified TCE model to account for the specific moderating factors that influence the relationship between asset specificity and entry modes in the case of services. They show that traditional TCE arguments are not directly applicable in the OS context as the peculiar nature of services needs to be taken into consideration when applying the conventional transaction-cost analysis and argue that OS would be of interest only for supplementary services that do not require a high level of professional skills and specialized know-how. In their study of offshore investment bank research activities, Grote and Täube (2007) similarly conclude that relatively low-level service activities are the only potential candidates for international relocation. Thus, TCE has emerged in the OS literature as a suitable model for describing choices of 
governance and optimal disaggregation-level decisions, especially related to standardized, noncore services that are shifted abroad to reduce costs.

In connection with the more recent offshoring of complex, knowledge-intensive service activities (Manning et al. 2008), scholars have progressively adopted additional lenses beyond the TCE approach to explain this development and conceptualize the challenges that have consequently emerged. In particular, the resource-based view (RBV) of the firm (Barney 1991) has acquired relevance in the OS literature from 2007, emerging as a suitable theoretical approach for identifying the pool of resources and capabilities needed to succeed in more complex OS implementations (Bunyaratavej et al. 2011; Javalgi et al. 2009). The work of Kedia and Lahiri (2007) on the distinction between tactical and strategic OS partnerships represents the first study where the RBV lens has been adopted together with the TCE framework to take this evolution into account. In their work, TCE is used to model tactical, cost-driven relocations of relatively commoditized service activities whose scope and value-creating potential remain limited. Conversely, the RBV approach is presented as the most appropriate theoretical perspective for framing the relocation of knowledge-intensive services that are critical to a company's creation of value and require distinctive capabilities as well as resource complementarities for their successful execution. Following Kedia and Lahiri (2007), other scholars have adopted a comparable multitheoretical approach, combining TCE and RBV arguments in order to model OS relocations (Boehe 2010; Martínez-Noya et al. 2012; Pereira and Anderson 2012; Roza et al. 2011; Vivek et al. 2009).

To assess the growing complexity of the OS phenomenon at the organizational level, increasingly researchers have grounded their work in the organization theory (OT) field, for instance using the organizational learning literature at the level of the company (Jensen 2009) and task (Luo et al. 2012; Narayanan et al. 2009) to examine OS processes over time. The innovation literature has framed the discourse on global sourcing of knowledge-intensive functions (Lewin et al. 2009; Nieto and Rodríguez 2011). The literature on modularity has been adopted to discuss the integration of globally distributed work (Srikanth and Puranam 2011). Research on organizational design has been applied to understand the creation of value in relocating services abroad (Jensen et al. 2013; Lampel and Bhalla 2011; Mukherjee et al. 2013). Six articles rooted in the OT field have adopted a co-evolutionary perspective to address the complexities of the OS phenomenon and stress its multidimensionality, especially in relation to its drivers (Lahiri and Kedia 2011; Lewin et al. 2009; Lewin and Volberda 2011; Manning et al. 2010; Martínez-Noya and García-Canal 2011; Sidhu and Volberda 2011).

Some scholars have acknowledged the limitations of traditional theoretical approaches and questioned their power in modeling OS. "Transaction-cost theory, while useful for analyzing each 'internalization versus externalization' decision, or analyzing each market entry mode choice, does not approach the puzzle of the firm as a global whole" (Contractor et al. 2010, p. 1428). Similarly, the RBV, while valuable for examining situations where firms have acquired ownership advantages, has been considered somewhat static with limited explanatory power for higher levels of disaggregation, which may dilute firm-specific resources and competencies (Contractor et al. 2010; Doh 2005). Recently, IB scholars have also pointed to the 
increasing commoditization of functions on a global scale (Manning 2013) as potentially eroding any benefits derived from managing resources and capabilities that should instead remain rare and difficult for competitors to imitate, thus calling into question one of the major implications of the RBV approach (Doh 2005).

In a critical assessment of the theoretical novelties associated with OS, some articles have focused on the limitations of traditional lenses and called for a rethink of the nature of the firm in an IB scenario characterized by organizational and geographical reconfiguration (Contractor et al. 2010; Hätönen and Eriksson 2009; Kenney et al. 2009; Lewin and Volberda 2011). Though we now have a better theoretical contextualization of OS than in the past, recent research confirms that the global sourcing of services remains an understudied phenomenon (Aykol et al. 2013; Bunyaratavej et al. 2011; Liesch et al. 2012), with relevant issues that still require a theoretical assessment (Manning 2014).

\section{Results}

To synthesize selected articles in order to map the OS literature, we applied an "Antecedents-Phenomenon-Consequences" logic. This guiding structure allowed us to proceed systematically in the analysis of published studies and their consequential mapping. The "Antecedents" category consists of articles that focus on the crucial drivers that trigger the emergence and growth of OS. The "Phenomenon" category includes articles that investigate the OS phenomenon and the distinctive elements of OS-related implementations. Finally, the "Consequences" category covers articles about the main effects associated with OS relocations.

This section contains a thematic analysis of the articles included in each category and specific subgroup as summarized in Table 3. While this should not be considered a definitive clustering of all IB studies focused on OS, it may be regarded as a useful way to group them. ${ }^{3}$ The review by Schmeisser (2013) of the offshoring phenomenon at large and the earlier work of Manning et al. (2008) on the offshoring of knowledge-intensive activities use similar groupings to categorize selected studies. On the one hand, this reinforces the relevance of the groupings used; on the other, it shows the need for an ad hoc assessment of those aspects that are associated uniquely with the OS literature.

\subsection{Antecedents of the OS Phenomenon}

Studies included in this category can be clustered according to the main level of analysis adopted when investigating the drivers of OS - the environmental and firm levels (see Table 3). As mentioned in the introduction, services cover a broad range of activities and several categorizations have been provided in the literature (Doh et al. 2009; Liu et al. 2011). Service activities have been characterized historically by four defining qualities: intangibility, heterogeneity in outputs, perishability, and

\footnotetext{
${ }^{3}$ For articles that could be associated with more than one of the subgroups listed, we made a judgment call and matched them with the subgroup that appeared most relevant to their focus.
} 
Table 3 Topics investigated in the OS literature

\begin{tabular}{|c|c|c|c|}
\hline Topic & References & Methodology & $\begin{array}{l}\text { Frequencies } \\
(\%)\end{array}$ \\
\hline \multicolumn{4}{|l|}{ Antecedents } \\
\hline \multirow[t]{3}{*}{$\begin{array}{l}\text { OS environmental } \\
\text { drivers }\end{array}$} & $\begin{array}{l}\text { Levy (2005), Lewin and Volberda (2011), } \\
\text { Lewin and Zhong (2013), Kshetri (2007) }\end{array}$ & Conceptual & $8(10 \%)$ \\
\hline & $\begin{array}{l}\text { Jandhyala (2013), Lewin et al. (2009), Nachum } \\
\text { and Zaheer (2005) }\end{array}$ & Empirical & \\
\hline & Zaheer and Manrakhan (2001) & Case study & \\
\hline \multirow[t]{2}{*}{ OS firm drivers } & Roza et al. (2011) & Empirical & $2(3 \%)$ \\
\hline & Lahiri and Kedia (2011) & Case study & \\
\hline \multicolumn{4}{|l|}{ Phenomenon } \\
\hline OS conceptualization & $\begin{array}{l}\text { Contractor et al. (2010), Doh (2005), Farrell } \\
\text { (2005), Hätönen and Eriksson (2009), Javalgi } \\
\text { et al. (2009), Jensen et al. (2013), Kenney } \\
\text { et al. (2009), Kotabe and Mudambi (2009), } \\
\text { Kundu and Merchant (2008), Liesch et al. } \\
\text { (2012), Parkhe (2007), Schmeisser (2013) }\end{array}$ & Conceptual & $12(15 \%)$ \\
\hline \multirow[t]{3}{*}{ OS rationale } & $\begin{array}{l}\text { Apte and Mason (1995), Kedia and Lahiri } \\
\text { (2007), Kedia and Mukherjee (2009), } \\
\text { Mukherjee et al. (2013) }\end{array}$ & Conceptual & $6(8 \%)$ \\
\hline & Murray and Kotabe (1999) & Empirical & \\
\hline & Mudambi and Venzin (2010) & Case study & \\
\hline \multirow[t]{2}{*}{$\begin{array}{l}\text { Emergence of IT and } \\
\text { IT-enabled service } \\
\text { providers }\end{array}$} & $\begin{array}{l}\text { Gao et al. (2010), Lahiri et al. (2012), } \\
\text { Narayanan et al. (2009), Tambe and Hitt } \\
\text { (2012), Walsh et al. (2012) }\end{array}$ & Empirical & $10(13 \%)$ \\
\hline & $\begin{array}{l}\text { Boussebaa et al. (2014), Demirbag et al. } \\
\text { (2012), Kshetri and Dholakia (2009), Pereira } \\
\text { and Anderson (2012), Soderberg et al. (2013) }\end{array}$ & Case study & \\
\hline \multirow[t]{2}{*}{$\begin{array}{l}\text { Focus on knowledge- } \\
\text { intensive services }\end{array}$} & $\begin{array}{l}\text { Boehe (2010), Demirbag and Glaister (2010), } \\
\text { Martinez-Noya and Garcia-Canal (2011), } \\
\text { Martinez-Noya et al. (2012), Nieto and } \\
\text { Rodríguez (2011) }\end{array}$ & Empirical & $7(9 \%)$ \\
\hline & $\begin{array}{l}\text { Lampel and Bhalla (2011), Mason and Leek } \\
\text { (2008) }\end{array}$ & Case study & \\
\hline \multirow[t]{3}{*}{ Location choice } & Graf and Mudambi (2005), Jain et al. (2008) & Conceptual & $12(15 \%)$ \\
\hline & $\begin{array}{l}\text { Bunyaratavej et al. (2007, 2008), Doh et al. } \\
\text { (2009), Ghani et al. (2014), Hahn et al. } \\
\text { (2011), Jensen and Pedersen (2011), Liu } \\
\text { et al. (2011), Zaheer et al. (2009) }\end{array}$ & Empirical & \\
\hline & Hätönen (2009), Manning et al. (2010) & Case study & \\
\hline \multirow[t]{3}{*}{ Governance choice } & Jensen and Petersen (2013) & Conceptual & $5(6 \%)$ \\
\hline & $\begin{array}{l}\text { Gooris and Peeters (2014), Hutzschenreuter } \\
\text { et al. (2011a), Luo et al. (2013) }\end{array}$ & Empirical & \\
\hline & Grote and Täube (2007) & Case study & \\
\hline $\begin{array}{l}\text { Coordination and } \\
\text { control mechanisms }\end{array}$ & $\begin{array}{l}\text { Luo et al. (2012), Manning et al. (2011) } \\
\text { Vivek et al. (2009) }\end{array}$ & $\begin{array}{l}\text { Empirical } \\
\text { Case study }\end{array}$ & $3(4 \%)$ \\
\hline
\end{tabular}


Table 3 continued

\begin{tabular}{|c|c|c|c|}
\hline Topic & References & Methodology & $\begin{array}{l}\text { Frequencies } \\
(\%)\end{array}$ \\
\hline \multirow{2}{*}{$\begin{array}{l}\text { Managing globally } \\
\text { distributed work }\end{array}$} & Srikanth and Puranam (2011) & Empirical & $5(6 \%)$ \\
\hline & $\begin{array}{l}\text { Chen et al. (2013), Kumar et al. (2009), Sidhu } \\
\text { and Volberda (2011), Srikanth and Puranam } \\
\text { (2014) }\end{array}$ & Case study & \\
\hline \multicolumn{4}{|l|}{ Consequences } \\
\hline OS performance & $\begin{array}{l}\text { Di Gregorio et al. (2009), Hutzschenreuter } \\
\text { et al. (2011b), Lahiri and Kedia (2009), } \\
\text { Larsen et al. (2013), Raman et al. (2013) }\end{array}$ & Empirical & $5(6 \%)$ \\
\hline $\begin{array}{l}\text { OS processes, } \\
\text { resources and } \\
\text { capabilities }\end{array}$ & $\begin{array}{l}\text { Jensen }(2009,2012) \text {, Manning (2014), Peeters } \\
\text { et al. (2014) }\end{array}$ & Case study & $4(5 \%)$ \\
\hline Total & & & $79(100 \%)$ \\
\hline
\end{tabular}

inseparability of production and consumption (Bessom and Jackson 1975; Di Gregorio et al. 2009; Erramilli and Rao 1990). According to this view, the intangibility of services stems from the fact that they are not physical products or artifacts, their composition is difficult to describe, and their transfer is problematic to measure. The heterogeneity of services results from their customization and specialization, with intra-sectoral heterogeneity originating from the diverse nature of each service provided. The perishability and the inseparability of production and consumption reflect the notion that services must generally be "consumed at or near the place and time of their production" (Doh et al. 2009, p. 930).

Services range from management consulting to software development and include financial, insurance, legal, and accounting activities to name just a few (Liu et al. 2011). Value activities that constitute the service component of a manufacturing process (e.g., product/process design) within the broader value chain of a company should also be considered services (Apte and Mason 1995). Drawing on existing OS research (Lahiri and Kedia 2009; Liu et al. 2011; Manning et al. 2011; Nieto and Rodríguez 2011; Rilla and Squicciarini 2011), we explicitly consider research and development $(\mathrm{R} \& \mathrm{D})$ activities as services in this review.

\subsubsection{Environmental Drivers}

The impossibility of separating the production and consumption of a service naturally prevented the geographic relocation of its production away from the consumer. Conventional wisdom as well as extensive research confirm that recent progresses in ICT have been a crucial antecedent of the OS phenomenon as they have relaxed this constraint by allowing companies to decouple the production and consumption of service activities and thus splinter them in a geographically dispersed value chain (Apte and Mason 1995; Bunyaratavej et al. 2008; Doh 2005; Dossani and Kenney 2007; Grote and Täube 2007; Jandhyala 2013; Murray and Kotabe 1999; UNCTAD 2004; Zaheer et al. 2009). Such advances have also 
increased the possibility of standardizing and storing services' outputs, further enlarging the scope of services that firms could relocate abroad successfully (Di Gregorio et al. 2009; Doh et al. 2009; Jandhyala 2013). To identify this emerging opportunity, terms such as tradability and offshorability of services have begun to appear in the literature (Doh et al. 2009; Lewin and Volberda 2011; Liu et al. 2011; Tambe and Hitt 2012).

Obviously, not all services have become good candidates for global disaggregation as a result of recent technological developments. OS research has focused on the specific characteristics that turn selected services into potentially offshorable activities, and generally converged on the notion that the higher the information intensity of a service activity (i.e., the proportion of time spent dealing with information relative to the total time devoted to the activity itself), the more likely it is that such activity is disaggregated and performed remotely (Apte and Mason 1995). Building on this, Nachum and Zaheer (2005) investigate how the lower costs of distance resulting from these technological developments alter companies' motivations to invest abroad, particularly in industries that are highly informationintensive. Their findings confirm that efficiency seeking represents the strongest driver behind OS-related implementations, while traditional market and resourceseeking motivations remain more relevant to industries that are not so informationintensive. Related work by Zaheer and Manrakhan (2001) describes how progresses in ICT influence the geographic dispersion of foreign investments by companies, suggesting on the one hand greater geographic dispersion of activities performed and, on the other, greater specialization and concentration of specific functions in selected locations.

At the country level, recent research on the relocation of information-intensive services investigates the impact of property rights protection on the institutional quality of host countries, illustrating how greater de facto property rights protection significantly increases the probability that a country will attract OS relocations from other regions (Jandhyala 2013). Using institutional theory, Kshetri (2007) further examines the offshore environment and identifies the mechanisms by which regulative and social rules, cultural habits, and social norms influence the flow of offshore outsourcing projects between countries. Lewin et al. (2009) identify the shortage of local talent as a crucial trigger for relocating knowledge-intensive services abroad and find empirical evidence that cost-related motivations do not play a role when it comes to offshoring such services. Consistent with their findings, other works recognize the emergence of a global workforce and the changing dynamics affecting the supply of and demand for high-skilled workers as antecedents of the OS phenomenon (Demirbag and Glaister 2010; Levy 2005). Lewin and Zhong (2013) show that, on the demand side, Western Europe and the United States have reported steady declines in the annual number of graduates in science, technology, engineering, and mathematics. Conversely, on the supply side, Asia, Latin America, and Eastern Europe have become the source of a larger pool of technical talent. The availability of qualified personnel in offshore locations has thus represented an increasingly important driver for the growth of the OS phenomenon, 
particularly in relation to the relocation of knowledge-intensive services (Bunyaratavej et al. 2007; Doh 2005; Manning et al. 2008).

\subsubsection{Firm Drivers}

Much of the early research on OS is aligned with the findings of Nachum and Zaheer (2005) and, consistent with general wisdom, shows that at the firm level the search for greater efficiency and cost reduction are the primary drivers behind OS implementations (Dossani and Kenney 2007; Farrell 2005; Grote and Täube 2007; Levy 2005). While still confirming the role of cost savings, recent research explores a wider array of motivations driving OS (Bunyaratavej et al. 2008; Doh et al. 2009; Kedia and Mukherjee 2009; Mudambi and Venzin 2010). Roza et al. (2011) consider resource and entrepreneurial motives beyond cost-related drivers, and suggest that resource motivations are key for both medium-sized and large firms while entrepreneurial drivers are most relevant to medium-sized firms. Empirical findings also confirm the role of competitors' actions in driving the decision to go offshore, as companies learn from and mimic rivals' moves, contributing to the emergence of OS-related clusters in selected offshore locations (Dossani and Kenney 2007; Gao et al. 2010; Javalgi et al. 2009; Manning et al. 2010). Other studies focus on the search for new knowledge that can lead to improved innovation performance (Martínez-Noya et al. 2012; Nieto and Rodríguez 2011). An extensive body of IB research demonstrates that path dependencies based on earlier experience and cumulative learning within host environments can drive internationalization strategies and lessen the liability of foreignness for firms operating across borders (Barkema et al. 1996; Chang and Rosenzweig 2001; Johanson and Vahlne 1977; Zaheer 1995). Published studies on OS confirm that companies adopt a progressive learning-by-doing approach rooted in uncertainty reduction for their OS ventures, gradually augmenting their exposure to OS investments by relocating more complex functions. Hence, experiential knowledge in OS practices is considered a relevant driver of OS implementations (Demirbag and Glaister 2010; Hätönen 2009; Hutzschenreuter et al. 2011a, b; Lewin and Peeters 2006; Martínez-Noya et al. 2012; Maskell et al. 2007).

Articles on OS antecedents often adopt a co-evolutionary perspective to shed light on the drivers triggering OS (e.g., Lahiri and Kedia 2011; Lewin and Volberda 2011; Lewin and Zhong 2013). Co-evolutionary theory essentially argues that firmlevel adaptation and environmental selection are profoundly interrelated in shaping organizational outcomes and that firms coevolve with each other and with their changing environments (Lewin and Volberda 1999). It suggests the simultaneous consideration of multiple levels of analysis and the appraisal of multidirectional causalities to understand business phenomena (Lewin et al. 1999). In the OS literature, this approach is deemed particularly suitable for capturing the complexity of OS and synthesizing the role of different drivers ranging from firm-level strategic intent to macro-level selection forces in a single framework (Lahiri and Kedia 2011; Lewin and Volberda 2011). 


\subsection{The OS Phenomenon}

The "Phenomenon" category naturally embodies the core of this review. As illustrated in Table 3, studies included in this category allow for a clustering in eight subgroups based on the specific topic investigated.

\subsubsection{OS Conceptualization and Rationale}

Eighteen articles primarily deal with the conceptualization and specific rationale of OS, where scholars contextualize OS within the broader IB field, define the relevant terminology, and investigate the logic behind OS-related implementations. Much of the work included in these subgroups remains at the conceptual level, stressing the need for IB authors, especially in the early stages, to identify the elements of theoretical novelty associated with OS. The first subgroup (OS conceptualization) contains studies that primarily adopt a general approach to the OS phenomenon and provide a conceptual assessment at a relatively broader level, while the second subgroup (OS rationale) comprises articles that investigate more closely the specific features of the OS rationale.

Nine articles in the OS conceptualization subgroup correspond to reviews (Hätönen and Eriksson 2009; Javalgi et al. 2009; Schmeisser 2013) and introductions to special issues dedicated to OS or related phenomena (Contractor et al. 2010; Jensen et al. 2013; Kenney et al. 2009; Kotabe and Mudambi 2009; Kundu and Merchant 2008; Parkhe 2007). Beyond assessing published research and introducing special issues, these works contribute to the OS literature by triggering scholarly discourse on OS-related topics and offering stimulating arguments to further our understanding of this phenomenon. For instance, Kenney et al. (2009) provide an inclusive assessment of the evolution of OS practices over time. Jensen et al. (2013) examine the international relocation of services, adopting an organization design perspective that allows them to distinguish among three important stages that characterize the organizational reconfiguration of each OS implementation: disintegration, relocation, and reintegration. Contractor et al. (2010) observe that the boundaries of several companies have simultaneously shrunk organizationally and expanded geographically, suggesting that there is an optimal level of disaggregation and dispersion for each company. They propose a fine-grained distinction among core, essential, and noncore activities, which may be of help in the finer slicing of firms' value chains. To model the decision on both the spatial distribution of activities and their potential outsourcing, Liesch et al. (2012) introduce the concept of a worldwide market for market transactions. In their conceptual work, they suggest that increased global availability of technical talent pushes companies to move noncore activities offshore and organize them using market-based solutions.

The second subgroup contains articles on the OS rationale, including the two seminal works that set the foundations for a taxonomy of disaggregation of services and an assessment of services' attributes that make their international relocation feasible and competitive (Apte and Mason 1995; Murray and Kotabe 1999). Apte and Mason (1995) distinguish three nonmutually exclusive actions undertaken in the 
production of any service - the manipulation of physical objects (physical actions), the collection, processing, and dissemination of symbols such as data entry (information actions), and the interaction with clients and other relevant actors (interpersonal actions). The authors posit that service activities can be globally disaggregated if the activity is information-intensive but the need for physical presence and customer contact is low, and the symbolic component of the activity is separable. They also identify two feasibility conditions: the technology to operate this separation is economically viable, and customers are culturally and legally prepared to accept such global disaggregation. Finally, they suggest that the relative strategic importance of the activity should be low and note that disaggregation mostly takes the form of outsourcing offshoring as companies realize that firms located abroad are generally more efficient at manipulating the relevant type of information.

Murray and Kotabe (1999) restrict their analysis to service firms and focus on the difference between core services (i.e., the necessary output of a service company) and supplementary services (i.e., additional services that are either essential for the execution of the core service or represent an improvement to the basic core service offered). The authors suggest that global sourcing becomes a viable option only for supplementary services as the separability of production and consumption is more likely and the company can leverage external providers' specific expertise. Their proposed framework posits a negative relationship between the asset specificity of a particular supplementary service and the likelihood of sourcing it globally. In other words, they argue that only supplementary services that do not require specific know-how or high-level professional activities may be relocated abroad.

Kedia and Mukherjee (2009) develop a general model rooted in the OLI paradigm to frame the relocation of any type of value activity that may be decoupled and relocated abroad, thus including offshorable services. They identify three advantages that can trigger OS relocations-disintegration, location-specific resourcing, and externalization. In what is of particular relevance for service activities, they acknowledge that disintegration advantages arise when companies can focus on their core capabilities and offshore noncore generic service activities that consume firm resources but do not contribute to the development of superior capabilities. Thus, their focus remains on peripheral noncore service activities as the primary candidates for offshore relocations. Recent work by Mukherjee et al. (2013) elaborates on this framework and, adopting an organization design perspective, conceptualizes the processes for an effective management of resources throughout the different offshoring stages.

Mudambi and Venzin (2010) provide a case-based analysis focused on the strategic nexus of offshoring and outsourcing decisions as they investigate the interdependent decisions about the control and location of selected parts of the value chain. They examine the magnitude of value chain disaggregation and the sequence of decisions to be taken by offshoring companies. While they maintain that there is no optimal decision sequence, in relation to the magnitude they conclude that the OS phenomenon progressively involves knowledge-intensive processes, although significant differences persist across industries. The authors also argue that it is 
crucial for firms to maintain tight control over high-value knowledge-intensive activities in the value chain regardless of the particular strategy they pursue.

Our analysis suggests that the pattern identified when considering the theoretical lenses adopted in the literature applies also to the OS rationale subgroup. While in the early phases scholars almost exclusively modeled the offshoring of standardized, noncore services (Apte and Mason 1995; Murray and Kotabe 1999), more recent research has also focused on the relocation of higher-skilled, core service activities (Kedia and Lahiri 2007; Mudambi and Venzin 2010).

\subsubsection{Emergence of IT and IT-Enabled Service Providers}

A relevant portion of articles focuses on the emergence of IT and IT-enabled service providers in offshore locations, and the related formation of the OS industry (e.g., Demirbag et al. 2012; Kshetri and Dholakia 2009; Lahiri et al. 2012). Still in its infancy a few years ago, this industry has become one of the most dynamic and quickly evolving industries, attracting growing interest in both practitioner and academic spheres (Kenney et al. 2009; Luo et al. 2012). The country that attracts the most attention is India (Demirbag et al. 2012; Gao et al. 2010; Soderberg et al. 2013) as it remains one of the top offshore choices (Lahiri et al. 2012; Luo et al. 2012), holding an iconic status for IT and IT-enabled services (Dossani and Kenney 2007; Pereira and Anderson 2012). Although known initially for providing basic IT services mostly associated with software development, Indian providers have leveraged recent technological developments to rapidly become a major competitive source for a wide gamut of services (Zaheer et al. 2009).

Recent research endorses India's National Association of Software and Services Companies (NASSCOM) as a critical actor in fomenting such growth (Kshetri and Dholakia 2009). Since its inception in 1988, NASSCOM has become the leading professional and trade association for India's OS sector, successfully helping its players achieve global legitimacy (Kshetri and Dholakia 2009). Along with the influence of NASSCOM, the role of official certifications in signaling the quality of service providers to potential customers has also been examined (Gao et al. 2010), with the capability maturity model (CMM) emerging as the most relevant accreditation of the OS industry (Gao et al. 2010; Narayanan et al. 2009; Soderberg et al. 2013). The CMM certification specifies five distinct maturity levels and serves both as a framework for improving software capabilities and as a highly renowned third-party recognition of quality in software development processes (Gao et al. 2010). Indian providers have improved their software development capabilities significantly over time. This higher degree of maturity is reflected in the complexity of services offered and formalized in CMM certifications (Lahiri and Kedia 2011). In 2009, $65 \%$ of all companies worldwide certified as having attained a level 5 capability were based in India, confirming the leading role of Indian firms in offering top-quality solutions for offshore IT and IT-enabled services (NASSCOM and McKinsey 2009).

The rapid expansion of the OS industry has also generated a number of challenges that have attracted scholarly attention. Demirbag et al. (2012) examine the sharp increase in labor turnover experienced in offshore sites and show that 
merely improving salaries and benefits does not solve the issue as this trend is primarily connected to drastic changes to the work culture, a general skills shortage, and relatively weak enforcement of employment contracts in the offshore environment. Another problem investigated by Walsh et al. (2012) is associated with customer perceptions of lower quality when a service is performed in offshore locations. The authors consider the case of call centers shifted to India and show that such centers are not necessarily related to lower performance outcomes. They suggest that service firms should prioritize a strong customer orientation among the offshore workforce to avoid potential downturns with customers. Still in the context of Indian-based call centers, Boussebaa et al. (2014) apply a postcolonial perspective to show how corporate "Englishization" may not only worsen communication problems but also lead to the reestablishment of colonial-style power relations between what they refer to as the "Anglosphere" and the "Rest."

Tambe and Hitt (2012) examine another important challenge, which is the composition of the workforce at home as a result of increased OS practices. The authors document how the availability of offshore IT workers has affected the skill composition of the IT workforce onshore. In their firm-level study of relocation of IT services from the United States to India, they show that companies using OS solutions are characterized consistently by a different onshore IT workforce that performs fewer tradable tasks. Their work illustrates how the emergent OS industry in India has triggered a shift in the United States towards an IT workforce predominantly focused on the interpersonal skills needed to perform more interactive services.

Seven articles on the growth of IT and IT-enabled service providers employ an explicit subsidiary/provider perspective (Gao et al. 2010; Lahiri et al. 2012; Pereira and Anderson 2012), one that has been practically neglected until recently (Luo et al. 2012; Soderberg et al. 2013). This change of perspective represents an innovative element in the OS literature and carries significant implications. First, it corroborates the increasing maturation of the OS industry, along with the growing relevance of its main players. Second, it suggests that companies operating on the supply side have evolved from low-cost local providers of standard services to global competitors capable of offering an array of high-value-added knowledgeintensive services (Lahiri and Kedia 2011; Lahiri et al. 2012; Narayanan et al. 2009; Soderberg et al. 2013).

Published works in this subgroup clearly point to the increasing influence of management capabilities and organizational capital in boosting offshore service providers' performance. Insights from recent studies also suggest that the relatively recent inclusion of high-value-added activities within the range of services offered has pushed providers to focus on intangible resources, identified as key determinants for overall outcomes (Lahiri et al. 2012; Luo et al. 2012). Thus, the importance of nurturing management capabilities and intangible resources in the offshore environment emerges as a crucial feature associated with the development of IT and IT-enabled service providers. 


\subsubsection{Focus on Knowledge-Intensive Services}

The existing research indicates that Western companies have increasingly offshored high-value-added knowledge-intensive service activities over time (Manning et al. 2008, 2011). As a result, a growing number of studies have focused on OS implementations requiring technical talent for their proper execution (e.g., Demirbag and Glaister 2010; Lewin et al. 2009; Martínez-Noya and García-Canal 2011; Nieto and Rodríguez 2011). Findings corroborate that offshoring such services involves a critical reconfiguration of activities at the company level (Lewin et al. 2009; Manning et al. 2008; Martínez-Noya and García-Canal 2011; Nieto and Rodríguez 2011). The international relocation of knowledge-based services is therefore presented as a growing practice in the OS scenario and framed as its most refined and challenging alternative.

At the regional level, Demirbag and Glaister (2010) point out that the size of the science and engineering talent pool in the offshore country (Lewin and Zhong 2013) is not the only factor shaping the migration of knowledge-intensive service activities. The authors posit that differences in knowledge infrastructures between headquarters and offshore regions as well as the political risk of the host environment also influence the international relocation of such services. Other issues include the organizational challenges of capturing the value created in the host environment and the hazards of knowledge leaks caused by weaker intellectual property regulations in offshore countries (Ellram et al. 2008; Henkel et al. 2013; Jandhyala 2013; Mariotti et al. 2010).

At the firm level, the OS literature converges on the notion that, as with many other functions (Gottfredson et al. 2005), the innovation process is often the result of integration among different and technologically separable stages. OS research documents how companies with thorough technological capabilities are more likely to relocate some knowledge-intensive service activities offshore (Martínez-Noya and García-Canal 2011; Martínez-Noya et al. 2012). Greater technological capabilities allow these companies to select, negotiate, and monitor their counterparts (Mayer and Salomon 2006) in order to transfer the necessary expertise (Martínez-Noya et al. 2012), and ultimately benefit from the offshore relocation of R\&D activities (Martínez-Noya and García-Canal 2011). Empirical results also show that prior experience matured via previous OS implementations and specific knowledge of the chosen offshore country significantly influence the geographic disaggregation of innovation processes (Demirbag and Glaister 2010; Lewin et al. 2009; Martínez-Noya and García-Canal 2011; Martínez-Noya et al. 2012). Nieto and Rodríguez (2011) look at how the offshore relocation of knowledge-intensive service activities contributes to firms' overall innovation performance. Their findings indicate that the relocation of $R \& D$ services offshore has a positive effect on firms' innovativeness, especially for product innovation. Accordingly, offshoring knowledge-intensive service activities can be seen as an important antecedent to the generation of new products and services.

As a result of the growing global sourcing of innovation, the OS literature has focused increasingly on the structural and managerial challenges associated with the management of knowledge-intensive supply networks across national borders 
(Lampel and Bhalla 2011; Mason and Leek 2008). Adopting a case-based approach, Mason and Leek (2008) investigate three components of dynamic business models (i.e., network structure, interfirm routines, and knowledge forms) to suggest that such networks require an effective interfirm and intrafirm transfer of knowledge in order to function well. Lampel and Bhalla (2011) focus on the potential disruption of a company's configuration of internal activities and conclude that knowledgeintensive supply networks must be configured carefully to account for interdependencies across offshore sites and potential "knowledge stickiness" at the individual activity level. The research of Boehe (2010) indicates that these interdependencies are shaped by the relationships that offshore units cultivate, not only with headquarters but also with the local counterparts within the host country.

\subsubsection{Location Choice}

The firm-level decision concerning where to migrate services abroad is one of the most examined topics in the literature. At the country level, beyond the availability of qualified workers (Graf and Mudambi 2005; Manning et al. 2010), the existing research indicates that labor costs, education, infrastructure standards, and institutional quality are other determinant factors for the offshore location choice (Bunyaratavej et al. 2007, 2008; Demirbag and Glaister 2010; Doh et al. 2009; Jain et al. 2008; Liu et al. 2011). The political hazards and cultural proximity of the host country also influence the selection of an offshore site (Demirbag and Glaister 2010; Doh et al. 2009; Graf and Mudambi 2005). Ethnic and social ties matter as well (Ghani et al. 2014) and, in some cases, can even exercise greater influence than cluster capabilities on OS location decisions (Zaheer et al. 2009).

At the more micro level, aligned with an increasing awareness that the specific nature of offshored activities is a primary determinant of location decisions (Graf and Mudambi 2005; Hätönen 2009), four studies focus on the attributes of offshored services and examine their influence on the OS location choice (Doh et al. 2009; Hahn et al. 2011; Liu et al. 2011; Zaheer et al. 2009). Doh et al. (2009) consider the degree of interactiveness, repetitiveness, and innovativeness of services and suggest that these influence the location choice by interacting with basic host country factors. Services with a strong interactive component tend to be offshored to countries with relatively higher levels of ICT infrastructure and high usage of the home country language. Conversely, services that have a strong repetitive component are more likely to be relocated to countries with relatively low wages and stable political environments. Liu et al. (2011) similarly categorize services according to their degree of interactiveness, routineness, and complexity and prove that more routine, less complex and less interactive services tend to be offshored more regularly. Moreover, they demonstrate that nonroutine, complex, and interactive services are more likely to be relocated to countries with better institutional quality.

Zaheer et al. (2009) also focus on key dimensions of tasks involved in the provision of services and group them into three categories: system-intensive and routine, people-intensive and routine, and people-intensive and creative. They suggest that firms tend to relocate services to clusters that offer higher levels of the 
specific capabilities needed to execute the particular service activity offshored. Furthermore, they show that system-based capabilities are more influential than either people-embedded routine or creative capabilities when it comes to attracting companies to a particular offshore cluster. Hahn et al. (2011) consider the basic distinction between lower and higher skill services and, similarly to Jensen and Pedersen (2011), who examine the offshoring of standardized versus advanced activities, show that discounted wages in the host (versus home) country have a stronger influence in determining the attractiveness of a particular offshore location for lower skill services. On the other hand, higher risks associated with the host (versus home) country tend to create a stronger deterrent to locating higher skill services. Hahn et al. (2011) also demonstrate that the factors driving near-shoring are qualitatively different from those involving far-flung locations. According to their findings, near-shoring remains a valuable strategic alternative to remote offshoring, as firms appear willing to trade higher gains, including labor costs, in order to alleviate the high risks of other dimensions such as political unrest.

\subsubsection{Governance Choice and Coordination and Control Mechanisms}

The governance mode represents a critical element in the firm-level OS decision. Companies can decide whether to organize offshored services internally, via a captive center; externally, by way of contractual arrangements with local providers; or through equity agreements with other partners. The degree of disaggregation remains a fundamental choice in defining OS implementations (Contractor et al. 2010; Hätönen and Eriksson 2009; Mudambi and Venzin 2010). Empirical results suggest that contractual arrangements with local providers often represent the way offshore basic service activities are initially organized (Lewin and Peeters 2006). As companies progressively move more complex services offshore, recent studies document that captive subsidiaries are used increasingly for OS operations in order to reduce the likelihood of potential knowledge leaks and maintain greater control over strategic activities (Hutzschenreuter et al. 2011a; Lewin et al. 2009; Mudambi and Venzin 2010; Nieto and Rodríguez 2011). Supporting this view, Grote and Täube (2007) posit that captive solutions are preferred even when relocating relatively low-level research activities in the investment bank industry as organizational proximity plays an important role in the performance of such tasks and can be guaranteed only through internalized offshore solutions.

In a recent assessment of governance mode decisions, Luo et al. (2013) focus on the specific task features of offshored services and their results further corroborate the observed trend. The authors show that, when offshored services are characterized by a high level of knowledge specialization, the preferred governance mode is a joint venture or partial ownership. As information security becomes more relevant and/or the integration between the provider and the client is greater, companies tend to opt for the captive solution. Conversely, when a process is more easily codifiable, the contractual agreement with a local offshore provider is confirmed as the preferred mode of governance. Gooris and Peeters (2014) focus on the different dimensions of home-host country distance to show that they influence the decision on the governance mode. Firms prefer to establish captive offshore service centers 
in the case of a great cultural and geographic distance while they privilege contractual agreements with local counterparts when facing a great institutional distance.

Jensen and Petersen (2013) focus on build-operate-transfer (BOT) contracts. Defined as outsourcing contractual agreements where the client firm has a call option to transfer operations in-house after a fixed period of time, BOTs are presented as a contractual novelty that potentially can combine the advantages of outsourced and captive OS operations. The authors develop a model to help identify scenarios where a BOT could be beneficial but recognize the potential hollowing out of knowledge competences as one of the major competitive risks faced by the provider.

Specifically associated with the outsourcing governance mode, the investigation of control and coordination mechanisms adopted by companies to manage their OS partnerships represents another thematic area in the literature. Luo et al. (2012) investigate the specific characteristics of service tasks that call for a higher degree of process integration between the offshore provider and its global client. They demonstrate that greater task complexity, security, and interdependence (i.e., connectivity, stickiness, and dependence) are associated positively with the level of integration between provider and client. Their work reinforces the notion that, in an increasingly complex scenario, offshore service providers play a crucial role in the effective integration of externalized service activities within a multinational network of geographically distributed value activities (Luo et al. 2012).

Manning et al. (2011) investigate the durability of offshore-outsourcing relationships and observe that providers trigger contract renewal through clientspecific investments in software, IT infrastructure and training, and by promoting a relational approach to control. Similar findings show that the accumulation of relationship experience often changes an OS partnership to one that is less transaction-cost-oriented (Vivek et al. 2009). The reviewed studies underline that, while the original objective may be tight control and cost reduction, over time trust and mutually created capabilities change the relationship to one involving resource and relational governance modes. Trustworthiness is therefore recognized as a highly relevant relational factor in the coordination and control of OS operations, especially when relocated services are complex and less standardized (Kedia and Lahiri 2007).

\subsubsection{Managing Globally Distributed Work}

Five articles adopt individual/team levels of analysis to focus on the micro-level challenges when service activities are partitioned and scattered globally. Kumar et al. (2009) challenge the traditional typology of task interdependence and propose a revised version that takes into consideration the spatial disaggregation characterizing globally distributed work. They develop an extended typology of interdependence and highlight the notion of stickiness as a crucial aspect of individual task interdependencies in geographically dispersed work settings.

Srikanth and Puranam (2011) also focus on the challenges associated with the integration of globally distributed work. They empirically show that investing in 
coordinating mechanisms can soften the negative effect of interdependence between offshore and onshore processes. Their work goes beyond the usual dichotomy of coordination strategies proposed in the literature-that is, the modularization of tasks or creation of extensive communication channels-and suggests that coordination mechanisms that rely on tacit coordination also contribute to weakening the negative impact of interdependence between offshore and onshore processes. These mechanisms, such as staffing geographically distributed teams with employees who have worked together before, allow for the formation of common ground across onshore and offshore individuals without the need for direct, ongoing communication, and thus can alleviate the challenges of distributed work. Recent research undertaken by the same authors (Srikanth and Puranam 2014) shows that tacit coordination mechanisms are extensively used when OS activities are organized via captive solutions while they are not as common when OS relocations are governed via contractual agreements with external parties. Chen et al. (2013) similarly stress the importance of communication in their study on the creation and transfer of knowledge offshore. They focus on shared mental models among onshore and offshore team members and show that these play a crucial role in knowledge transfer and building. Their case-based analysis indicates that informal communication, close interaction, and coordination among individuals staffed onshore and offshore facilitate the creation of these shared mental models and thus enhance the creation and transfer of knowledge.

Sidhu and Volberda (2011) also examine the challenges related to the integration and coordination of activities across geographically dispersed sites, but their microlevel analysis of a leading IT service provider's OS implementation in India leads to different conclusions from other studies reviewed. Their findings suggest that the promotion of task coordination can generate political conflict within the focal organization and negatively affect performance. The authors argue that managers involved in OS projects should nurture and leverage differences in skills, language, and culture among onshore and offshore team members rather than enforcing standardization through a formal coordination across organization sites.

\subsection{Consequences of the OS Phenomenon}

The nine articles in this category can be divided into two subgroups. The first focuses on OS performance, primarily using cost and sales-related measurements (Di Gregorio et al. 2009; Hutzschenreuter et al. 2011b; Lahiri and Kedia 2009; Larsen et al. 2013; Raman et al. 2013). The second set deals with the particular processes, resources, and capabilities resulting from OS implementations (Jensen 2009, 2012; Manning 2014; Peeters et al. 2014). Before moving to the analysis of studies included in these two subgroups, it is worth noting that an important country-level consequence of the growth of the OS phenomenon is the emergence of clusters formed by highly specialized service providers in various emerging economies. While our review primarily focuses on India, recent studies have also documented the creation of similar clusters in other countries such as Argentina, Brazil, China, Mexico, and Russia (Manning 2013; Manning et al. 2010). 


\subsubsection{OS Performance}

In the first subgroup, Hutzschenreuter et al. (2011b) focus on the time needed to achieve expected cost savings and targeted levels of service. The authors show that firm-specific OS experience and path dependencies, publicly available knowledge, cultural distance between home and host country as well as the chosen governance mode play a role in determining the time needed to achieve desired outcomes. Larsen et al. (2013) also refer to a cost-related measure in their assessment of OS performance and focus on estimation errors driven by hidden costs as a potential negative outcome of OS relocations. Their empirical study proves that costestimation errors are more likely in the presence of greater configuration complexity for captive subsidiaries and task complexity when a service is outsourced offshore. That said, they show that experience and a strong orientation towards organizational design in devising the OS strategy can reduce the likelihood of such errors. Finally, Di Gregorio et al. (2009) focus on the overall sales-related impact of OS outsourcing implementations and show a markedly positive effect on export performance, associated with a greater extent and scope of sales internationalization.

While these articles look at performance from the viewpoint of the headquarters/client, Lahiri and Kedia (2009) adopt the providers' perspective to illustrate how their internal resources (i.e., human capital, organizational capital, and management capability) positively affect their sales-based performance. The authors also demonstrate that the quality of the partnership between onshore and offshore companies, contextualized as an important relational resource, partially mediates and moderates this association. In a similar vein, Raman et al. (2013) investigate the effect of partnership quality to document that it has a mediation effect on the impact of talent management and a global mindset on OS performance. Their findings suggest that it is crucial for offshore service providers to establish and maintain high-quality partnerships with their foreign clients in order to enhance performance.

\subsubsection{OS Processes, Resources and Capabilities}

In the second subgroup of articles focusing on the resource-related consequences of OS implementations, Jensen (2009) adopts a learning perspective to posit that the relocation of advanced services abroad leads to a process of strategic transformation and organization change in both home and host firms. His findings highlight that learning paths evolve over time, often diverging from initial expectations, and both onshore and offshore companies can learn to upgrade their organizations and business processes. More recent research (Jensen 2012) further investigates the resource-building process in the client firm to show that, while certain factors associated with the OS implementation facilitate such a process (e.g., trust building, partnership commitment), others hinder it (e.g., time compression diseconomies).

Peeters et al. (2014) frame the sourcing of services from offshore countries as a management innovation that companies need to adopt and adapt internally to fit the new practice to their existing organization. Obviously, not all companies succeed in this process. The authors argue that success versus failure in this respect depends not 
only on the different configurations of absorptive capacity routines but also, crucially, on the managerial attention towards the management innovation as well as the organizational legitimacy of the new practice. Their case-study analysis shows that both managerial attention and organizational legitimacy help the rapid and smooth adaptation and adoption process by stimulating organization members to create support for and dedicate effort to OS activities and develop an appropriate configuration of absorptive capacity routines.

Manning (2014) focuses on how firms respond to implementation challenges that can emerge once OS ventures have been established. The findings of his multiple case-study analysis suggest that companies respond to challenges in three distinct ways: mitigating, tolerating, or relocating. If the focal firm perceives the cause of the challenge to be internal, then its most likely response is to either mitigate or tolerate. Conversely, when the cause of the challenge is regarded as being external, there is a greater probability that the focal firm will respond to such a challenge by either tolerating or relocating. The author also shows that the strategic objective driving the OS venture contributes to the choice of response. For instance, when OS activities are primarily driven by a cost-cutting rationale, firms are more likely to respond to challenges by either tolerating or relocating.

\subsection{Ad Hoc Review of the IS Literature}

Beyond the IB field considered by this review, other literatures have examined OSrelated topics and may thus provide a particularly stimulating reference for IB scholars to further our understanding of the OS phenomenon. Although our review is deliberately focused on IB research, the IS literature deserves special mention as "the offshoring of information systems and services has been one of the most discussed phenomena in IS in recent years" (King and Torkzadeh 2008, p. 205). Our analysis of the 18 selected articles showed that more than half consider the individual/team levels of analysis and adopt a subsidiary/client perspective to examine OS implementations. This corroborates the different angle that the IS literature has prioritized in investigating OS and the relevance of its contributions for a profound assessment of the mechanisms adopted by companies to deal with OS and, in particular, the management of geographically distributed teams.

Williams (2011) focuses on knowledge transfer in the OS outsourcing case to show that formal training and client embedment have a positive influence on clientvendor knowledge transfer. He demonstrates that offshore engineers with previous onshore experience contribute to improving overall knowledge transfer. Oshri et al. (2008) also examine knowledge transfer in globally distributed teams to investigate the role of transactive memory developed by team members who establish codified and personalized directories, such as frequent teleconferencing and occasional short visits, in order to overcome the challenges associated with globally distributed teams. The recent study by Zimmermann and Ravishankar (2014) also focuses on knowledge transfer and shows that the development of social capital together with onshore personnel's ability and willingness to cooperate with the offshore team represent crucial aspects of an effective knowledge transfer. 
The study of Vlaar et al. (2008) examines how onshore and offshore team members engage in acts of sense making to understand their tasks and respond congruently to stimuli received. The authors observe that ICT tools are employed to transcend the need for direct communication and enable tacit coordination, identified by Srikanth and Puranam (2011) as a key mechanism to integrate globally distributed work. Levina and Vaast (2008) similarly focus on the close collaboration among onshore and offshore team members necessary to accomplish complex OS implementations and suggest that achieving an effective collaboration depends on specific middle managers who engage in boundary-spanning practices across firm and country borders. Kotlarsky et al. (2014) further contribute to this stream of research by illustrating the coordinative role played by codification. The authors suggest that codification is not only a static concept that is uniquely associated with the replication and diffusion of knowledge across sites but it contains a more dynamic aspect that enables the reciprocal interrelating of expertise needed when tasks are unstructured.

\section{Discussion and Avenues for Future Research}

We begin this section by introducing a framework (see Fig. 2) for understanding the OS phenomenon. The proposed framework reflects the "Antecedents-PhenomenonConsequences" logic adopted in the review process, synthesizes the body of research considered, and ultimately offers an intuitive representation of the OS

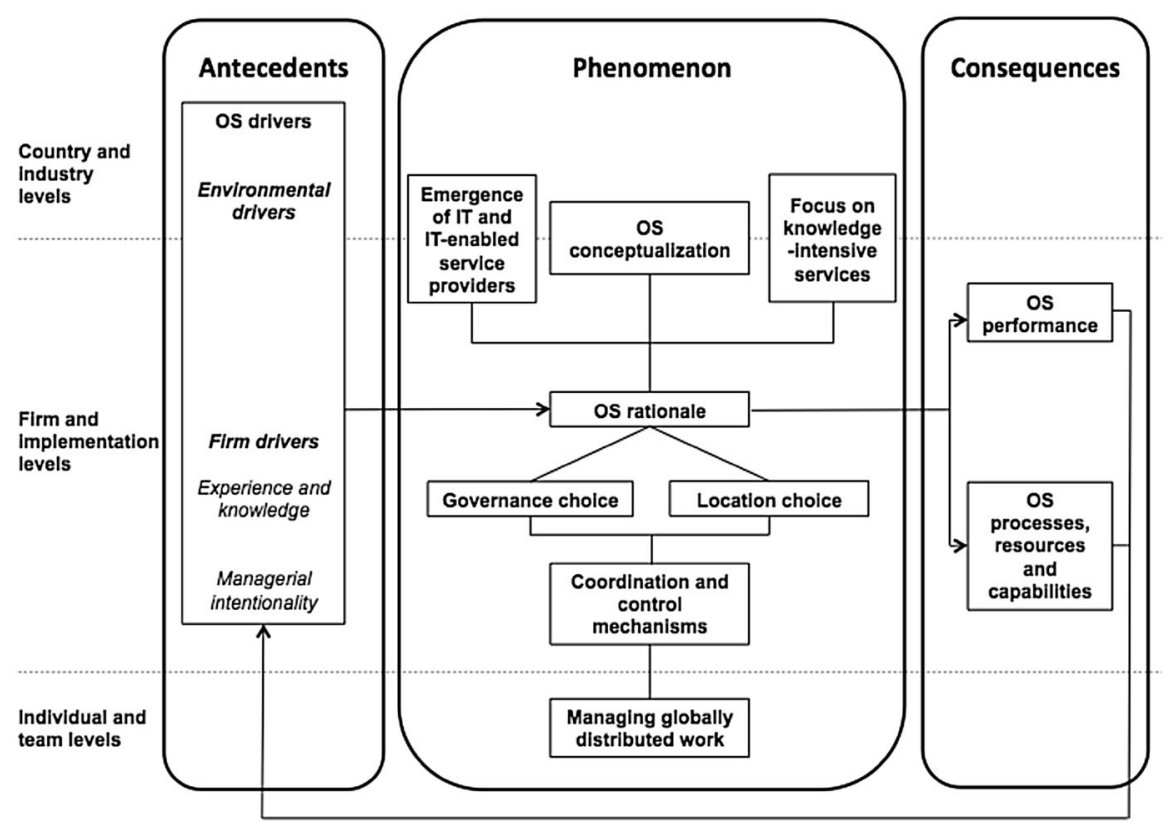

Fig. 2 An organizing framework for understanding OS 
multilevel mechanisms and critical thematic areas. It is based on the subgroups of studies identified in the previous section, and builds upon and expands the coevolutionary model of the broader offshoring decision set out in Lewin and Volberda (2011) as well as the conceptual work of Schmeisser (2013) on the offshoring phenomenon at large. In particular, our further development of the integrative framework of Schmeisser (2013) contributes to the specific contextualization of OS within the broader offshoring phenomenon and helps to visualize the peculiarities that are uniquely associated with OS. As previously mentioned when introducing the groupings of articles, the proposed clustering should not be regarded as a definitive categorization of OS research but rather considered as a useful mapping of the literature. Subgroups are linked via arrows when they belong to different categories to suggest the direction of causality underlying the "Antecedents-Phenomenon-Consequences" logic (Schmeisser 2013). They are instead connected via straight lines when pertaining to the same category to suggest their connection.

The co-evolutionary approach has been acknowledged as particularly helpful in modeling the multidimensionality of the OS phenomenon and describing the connectedness rather than just the significance of each of the dynamics at play, especially in relation to OS antecedents (Manning et al. 2008). In the proposed model, firm-level managerial intentionality, experience, and knowledge (Hutzschenreuter et al. 2007; Lewin et al. 2009) are therefore considered jointly with institutional-level forces (Lewin and Volberda 2011) and emerging global trends (Manning et al. 2008, 2010) as crucial OS triggers. To model the co-evolutionary processes recalled in the literature (Lahiri and Kedia 2011; Lewin et al. 2009; Lewin and Volberda 2011; Manning et al. 2010; Martínez-Noya and García-Canal 2011; Sidhu and Volberda 2011), the "Consequences" category is linked to the "Antecedents," as companies learn from previous OS-related implementations and institutional forces are shaped by these path dependencies (Hutzschenreuter et al. 2007). In relation to this, the existing research confirms that the acquisition of experience in OS ventures and the related development of resources and capabilities in the offshore context are important drivers behind the firm-level decision to initiate new OS implementations (Demirbag and Glaister 2010; Hätönen 2009; Hutzschenreuter et al. 2011a, b; Lewin and Peeters 2006; Martínez-Noya et al. 2012; Maskell et al. 2007).

Moreover, the identification of the distinct levels of analysis in the framework helps to grasp the multidimensional characteristic of OS as well as visualize each subgroup's emphasis on a particular level of analysis. While several studies adopt multiple levels of analysis and there is no exact matching between all articles belonging to a specific subgroup and a single level, our review of the literature suggests the emergence of a clear pattern that the framework helps to visualize. This contributes to a more nuanced contextualization of the OS phenomenon and helps to identify those levels of analysis that have been relatively overlooked in the past. Using the proposed model as a reference framework, in the remainder of this section we will elaborate on the findings of our review, discuss emerging topics on the OS frontier, and identify areas of research that would benefit from further investigation. 
The "Antecedents" category contains articles focused on the main drivers triggering the emergence and growth of the OS phenomenon. Researchers have considered a host of factors, primarily at the macro level. That said, our analysis suggests that the role of managerial intentionality has received relatively limited scholarly attention, in particular the impact of formal strategic thinking on the definition of OS implementations (Martínez-Noya and García-Canal 2011; Mudambi and Venzin 2010). Managerial intentionality represents a crucial element of the co-evolutionary approach and a significant aspect of the broader offshoring decision (Hutzschenreuter et al. 2007; Lewin and Volberda 2011) that has not been explicitly considered in previous reviews focused on offshoring-related topics. In the context of our study, OS can be framed as a firm-level choice for relocating selected service activities abroad. Despite this, our results document that the notion of international strategy is used only marginally when assessing this relevant decision (Martínez-Noya and García-Canal 2011; Massini et al. 2010; Mudambi and Venzin 2010). Among the possible causes are that, first, the OS phenomenon has only recently attracted the attention of top management teams, as a result of the increasingly complex activities being relocated abroad. Especially at the very early stages, OS has represented a bottom-up organizational phenomenon, characterized by the absence of corporate-wide strategies guiding OS implementations (Lewin and Peeters 2006). Second, the difficulties of collecting valuable cross-border data have contributed to limit the number of studies focused on firms' international strategies (Ghemawat 2008). Accordingly, future studies should focus on the impact of formal strategic thinking in shaping OS implementations and investigate companies' broader strategic vision relative to OS ventures. Scholars should also address in greater detail the link between the consequences and antecedents of OS implementations, for instance by looking at how the development of management capabilities both onshore and offshore influences the strategic decision making behind prospective OS relocations and potentially determines the offshoring of new services.

The "Phenomenon" category contains articles investigating the OS phenomenon and the distinctive elements of OS-related implementations. Our analysis of studies focused on the OS conceptualization and rationale shows that scholars have proposed insightful taxonomies of service disaggregation and identified relevant attributes that turn services into potential candidates for global disaggregation. Having said that, a comprehensive theoretical assessment of the OS rationale is still lacking, especially because of the finely variegated nature of service activities that can be offshored (Bunyaratavej et al. 2011). For instance, Kumar et al. (2009, p. 646) stress that "the guidelines for global distribution of work are primarily experience-driven, ad hoc, and without a cohesive theoretical base." Our review also shows that most studies explicitly focused on the specific task attributes associated with offshored services examine their impact on the location choice (Doh et al. 2009; Hahn et al. 2011; Jensen and Pedersen 2011; Zaheer et al. 2009). Future research should further our understanding of how task characteristics can influence other relevant aspects of OS implementations, such as the adoption of specific coordination and control mechanisms. 
Our analysis suggests that the increased complexity of offshored services has shifted scholarly attention to the specific management capabilities needed to deal with the challenges of OS implementations (Lahiri et al. 2012; Luo et al. 2012). Building on this emerging focus, future studies should examine how companies succeed in developing new and agile organizational forms to allow for successful offshoring of complex, knowledge-intensive services, and how this is crucially influenced by the attributes of relocated tasks. Scholars should also examine entrepreneurial action both onshore and offshore, in order to nurture the coordination capabilities needed to orchestrate such a dispersed network of activities.

Our assessment of the OS literature in terms of the specific perspectives embraced by scholars documents that OS studies have increasingly adopted a subsidiary/provider perspective. The growing focus on the specific role of subsidiaries and providers in the offshore environment is another emerging element in the OS literature that is highly relevant to future research. As the nature of OS continues to evolve, scholars should shift their angle to heed the competencies required to manage and govern global networks from the perspective of local offshore providers. Our analysis indicates that in recent years scholars have gone beyond the usual migration of service activities from Western countries to lowercost regions to address the global aspects of the OS phenomenon. Future studies should strengthen their focus on the relocation of OS activities triggered by firms headquartered outside Western Europe and the United States. In this vein, the emerging trend of reverse offshoring, according to which firms based in countries that offer offshore services open offices in their clients' region to broaden their own activities (Bunyaratavej et al. 2011), represents a fruitful avenue for future research.

The management of globally distributed teams emerges as a relevant topic in the OS literature. Yet, our review shows that the management of geographically distributed work appears as a relatively understudied theme and the individual/team levels as comparatively underutilized angles. The identification of these patterns has significant implications for future research on OS. Building on the results of our work, we suggest that future micro-level research focused on the characteristics of successful work design and the optimal partitioning of tasks across offshore sites has the potential to lead to very insightful findings. In particular, scholars should focus on the specific team-level capabilities needed to manage a geographically dispersed network of complex service activities. As such, the development of these capabilities will be central to the future of OS practices and consequently a very promising avenue for future research. Drawing from the ad hoc analysis of the IS literature presented in the previous section, the individual mechanisms developed by teams to secure effective knowledge transfer and the specific role of individual boundary spanners emerge as key elements of the company-level orchestration of geographically distributed service activities. These themes should also become the focus of increased scholarly attention within the IB field in the future.

Finally, the "Consequences" category contains articles on the main effects associated with OS relocations. Although reviewed studies in this group contain valuable insights, we believe this area of research remained relatively understudied. As the OS phenomenon is still in its early stages, scholars have paid comparatively 
more attention to the antecedents rather than the outcomes of OS activities. The OS processes, resources, and capabilities subgroup should attract more research since, as our review indicates, the development of capabilities to manage knowledgeintensive OS relocations and the specific operational processes adopted to deal with this enhanced complexity will become even more central in the future. As suggested by Jensen et al. (2013), a finer-grained assessment of the reintegration stage following the disintegration and reconfiguration phases characteristic of each OS implementation remains critical for an in-depth assessment of the OS phenomenon, and should become the focus of greater research efforts.

Four studies mention the "hollowing out" of client firms' competencies as a potential negative consequence of OS implementations (Jensen et al. 2013; Kedia and Mukherjee 2009; Kotabe and Mudambi 2009; Mudambi and Venzin 2010). As a result of the high degree of specialization involved in the extensive outsourcing of knowledge-intensive activities, offshore vendors can potentially erode client firms' core competencies. Mostly considered in connection with the international relocation of manufacturing activities (Kotabe 1989; Kotabe et al. 2008), the "hollowing out" is correctly framed as a potentially disruptive consequence of OS implementations (Jensen et al. 2013; Kotabe and Mudambi 2009; Mudambi and Venzin 2010). Yet, a rigorous investigation of the "hollowing out" effect associated with OS and the organizational responses adopted by companies to prevent this or at least lower its likelihood is still lacking, representing another promising avenue for future research.

Despite increasing media coverage (Booth 2013), the issue of reshoring is an additional "Consequences"-related topic that has been overlooked in the OS literature. Companies that relocate specific services abroad can choose to "reshore" them back to their home countries. Such a decision may be triggered by a multitude of reasons, for instance lower-than-expected performance outcomes in the offshore environment, political pressures at home, or overly complex coordination costs associated with the coordination of geographically dispersed services. While the case for a global reverse flow of OS investments has been discussed in the press and in practitioners' outlets (Booth 2013; Porter and Rivkin 2012), the OS literature has not yet examined this precise topic, which would therefore benefit from further investigation. Another topic that has attracted increasing attention but has not yet been considered in OS research is the mega-trend of "Big Data". Future studies should therefore investigate whether the "Big Data"-movement relates to the OS phenomenon and, if so, how companies can utilize OS practices to make the most of the enhanced digitalization and integration/interconnectedness associated with this emergent trend.

\section{Conclusion}

Previous literature reviews assessed research on topics related to the OS phenomenon (Bunyaratavej et al. 2011; Hätönen and Eriksson 2009; Rilla and Squicciarini 2011; Schmeisser 2013; Youngdahl and Ramaswamy 2008). Despite the various merits of these works, none of them offered an up-to-date and systematic 
review of the OS literature. The main purpose of this article is to fill this gap and contribute to the IB discipline by providing a systematic review of the body of IB research focused on the OS phenomenon. We compile and synthesize extant IB research on OS, present a structured map of the literature, and elaborate an organizing framework for a more nuanced appraisal of OS. We also identify emerging topics on the OS frontier and suggest promising avenues for future research.

Our review aims to offer a systematic repository of knowledge for all IB scholars interested in learning more about the OS phenomenon. For IB researchers currently engaged in OS-related studies, our work provides a stimulating reference point to appraise the relevant literature. The descriptive analysis of the articles sampled helps to make sense of the body of IB research on OS and identify its key attributes. The assessment of the theoretical lenses provides the reader with the opportunity to appreciate how the theoretical discourse on OS has changed over time. Our further development of the integrative framework of Schmeisser (2013), focused on the broader offshoring phenomenon, helps to organize the stock of existing knowledge on OS and sheds light on the peculiarities of the OS scenario. The discussion on the emerging patterns presented in the previous section contributes to the identification of a unique set of aspects associated with the OS literature that will be critical for the future of this body of research.

The major findings of the studies reviewed offer insights to fundamental questions related to OS. Still, many relevant issues require further investigation. The systematic analysis of the received literature shows that emerging aspects on the OS frontier deserve greater attention in order to appreciate fully the idiosyncrasies of this growing and continuously evolving phenomenon. Some of the key points that merit consideration include the evolution of service providers and their related industry, as well as the need to nurture organizational capabilities in the offshore environment in order to manage the complexities inherent in OS implementations. To this end, the subsidiary/provider perspective emerges as an essential way to appreciate the global implications of the OS phenomenon. In terms of the levels of analysis adopted, our review shows that the individual/team level has been relatively overlooked in OS research, which points to the notion that micro-level research on the management of geographically distributed work is one of the most promising areas for future investigations.

As the global sourcing of services continues to grow and evolve, this review reveals that much work remains for those IB scholars interested in this multifaceted phenomenon, which is expected to affect firms' cross-border activities to an even greater extent in upcoming years.

Acknowledgments The authors would like to thank Co-Editor-in-Chief Michael-Jörg Oesterle and the two anonymous reviewers for their insightful and constructive comments throughout the review process.

Open Access This article is distributed under the terms of the Creative Commons Attribution 4.0 International License (http://creativecommons.org/licenses/by/4.0/), which permits unrestricted use, distribution, and reproduction in any medium, provided you give appropriate credit to the original author(s) and the source, provide a link to the Creative Commons license, and indicate if changes were made. 


\section{References}

Apte, U. M., \& Mason, R. O. (1995). Global disaggregation of information-intensive services. Management Science, 41(7), 1250-1262.

Aykol, B., Palihawadana, D., \& Leonidou, L. C. (2013). Research on the import activities of firms 1960-2010: review, assessment, and future directions. Management International Review, 53(2), $215-250$.

Barkema, H. G., Bell, J. H., \& Pennings, J. M. (1996). Foreign entry, cultural barriers, and learning. Strategic Management Journal, 17(2), 151-166.

Barney, J. B. (1991). Firm resources and sustained competitive advantage. Journal of Management, 17(1), 99-120.

Bessom, R. M., \& Jackson, D. W. (1975). Service retailing-strategic marketing approach. Journal of Retailing, 51(2), 75-84.

Boehe, D. M. (2010). Captive offshoring of new product development in Brazil: how does arbitrage influence local, collaborative relationships? Management International Review, 50(6), 747-773.

Booth, T. (2013). Here, there and everywhere. The Economist, January 19, 11-16.

Boussebaa, M., Sinha, S., \& Gabriel, Y. (2014). Englishization in offshore call centers: a postcolonial perspective. Journal of International Business Studies, 45(9), 1152-1169.

Buckley, P. J., \& Lessard, D. R. (2005). Regaining the edge for international business research. Journal of International Business Studies, 36(6), 595-599.

Bunyaratavej, K., Doh, J., Hahn, E. D., Lewin, A. Y., \& Massini, S. (2011). Conceptual issues in services offshoring research: a multidisciplinary review. Group and Organization Management, 36(1), 70-102.

Bunyaratavej, K., Hahn, E. D., \& Doh, J. P. (2007). International offshoring of services: a parity study. Journal of International Management, 13(1), 7-21.

Bunyaratavej, K., Hahn, E. D., \& Doh, J. P. (2008). Multinational investment and host country development: location efficiencies for services offshoring. Journal of World Business, 43(2), 227-242.

Chan, K. C., Fung, H. G., \& Leung, K. (2006). International business research: trends and school rankings. International Business Review, 15(4), 317-338.

Chang, S. J., \& Rosenzweig, P. (2001). The choice of entry mode in sequential foreign direct investment. Strategic Management Journal, 22(8), 747-776.

Chen, J. H., McQueen, R. J., \& Sun, P. Y. T. (2013). Knowledge transfer and knowledge building at offshored technical support centers. Journal of International Management, 19(4), 362-376.

Contractor, F. J., Kumar, V., Kundu, S. K., \& Pedersen, T. (2010). Reconceptualizing the firm in a world of outsourcing and offshoring: the organizational and geographical relocation of high-value company functions. Journal of Management Studies, 47(8), 1417-1433.

Demirbag, M., \& Glaister, K. W. (2010). Factors determining offshore location choice for R\&D projects: a comparative study of developed and emerging regions. Journal of Management Studies, 47(8), 1534-1560.

Demirbag, M., Mellahi, K., Sahadev, S., \& Elliston, J. (2012). Employee service abandonment in offshore operations: a case study of a US multinational in India. Journal of World Business, 47(2), 178-185.

Di Gregorio, D., Musteen, M., \& Thomas, D. E. (2009). Offshore outsourcing as a source of international competitiveness for SMEs. Journal of International Business Studies, 40(6), 969-988.

Doh, J. P. (2005). Offshore outsourcing: implications for international business and strategic management theory and practice. Journal of Management Studies, 42(3), 695-704.

Doh, J. P., Bunyaratavej, K., \& Hahn, E. D. (2009). Separable but not equal: the location determinants of discrete services offshoring activities. Journal of International Business Studies, 40(6), 926-943.

Dossani, R., \& Kenney, M. (2007). The next wave of globalization: relocating service provision to India. World Development, 35(5), 772-791.

Dunning, J. H. (2000). The eclectic paradigm as an envelope for economic and business theories of MNE activity. International Business Review, 9(2), 163-190.

Ellis, P. D., \& Zhan, G. (2011). How international are the international business journals? International Business Review, 20(1), 100-112.

Ellram, L. M., Tate, W. L., \& Billington, C. (2008). Offshore outsourcing of professional services: a transaction cost economics perspective. Journal of Operations Management, 26(2), 148-163. 
Erramilli, M. K., \& Rao, C. P. (1990). Choice of foreign-market entry modes by service firms-role of market knowledge. Management International Review, 30(2), 135-150.

Farrell, D. (2005). Offshoring: value creation through economic change. Journal of Management Studies, 42(3), 675-683.

Gao, G. D., Gopal, A., \& Agarwal, R. (2010). Contingent effects of quality signaling: evidence from the Indian offshore IT services industry. Management Science, 56(6), 1012-1029.

Ghani, E., Kerr, W. R., \& Stanton, C. (2014). Diasporas and outsourcing: evidence from oDesk and India. Management Science, 60(7), 1677-1697.

Ghemawat, P. (2008). Reconceptualizing international strategy and organization. Strategic Organization, 6(2), 195-206.

Gomez-Mejia, L. R., \& Balkin, D. B. (1992). Determinant of faculty pay: an agency theory perspective. Academy of Management Journal, 35(5), 921-955.

Gooris, J., \& Peeters, C. (2014). Home-host country distance in offshore governance choices. Journal of International Management, 20(1), 73-86.

Gottfredson, M., Puryear, R., \& Philips, S. (2005). Strategic sourcing-from periphery to the core. Harvard Business Review, 83(2), 132-139.

Graf, M., \& Mudambi, S. M. (2005). The outsourcing of IT-enabled business processes: a conceptual model of the location decision. Journal of International Management, 11(2), 253-268.

Grote, M. H., \& Täube, F. A. (2007). When outsourcing is not an option: international relocation of investment bank research-or isn't it? Journal of International Management, 13(1), 57-77.

Hahn, E. D., Bunyaratavej, K., \& Doh, J. P. (2011). Impacts of risk and service type on nearshore and offshore investment location decisions. Management International Review, 51(3), 357-380.

Hätönen, J. (2009). Making the locational choice: a case approach to the development of a theory of offshore outsourcing and internationalization. Journal of International Management, 15(1), 61-76.

Hätönen, J., \& Eriksson, T. (2009). 30+ years of research and practice of outsourcing — exploring the past and anticipating the future. Journal of International Management, 15(2), 142-155.

Henkel, J., Baldwin, C. Y., \& Shih, W. (2013). IP Modularity: profiting from innovation by aligning product architecture with intellectual property. California Management Review, 55(4), 65-82.

Hutzschenreuter, T., Lewin, A. Y., \& Dresel, S. (2011a). Governance modes for offshoring activities: a comparison of US and German firms. International Business Review, 20(3), 291-313.

Hutzschenreuter, T., Lewin, A. Y., \& Dresel, S. (2011b). Time to success in offshoring business processes: a multi level analysis. Management International Review, 51(1), 65-92.

Hutzschenreuter, T., Pedersen, T., \& Volberda, H. W. (2007). The role of path dependency and managerial intentionality: a perspective on international business research. Journal of International Business Studies, 38(7), 1055-1068.

Inkpen, A. C. (2001). A note on ranking the international business journals. Journal of International Business Studies, 32(1), 193-196.

Jain, N. K., Kundu, S. K., \& Niederman, F. A. (2008). Offshoring propensity in information technology services: a firm and country level analysis. Management International Review, 48(4), 447-461.

Jandhyala, S. (2013). Property rights and international investment in information technology services. Strategic Management Journal, 34(7), 877-889.

Javalgi, R. G., Dixit, A., \& Scherer, R. F. (2009). Outsourcing to emerging markets: theoretical perspectives and policy implications. Journal of International Management, 15(2), 156-168.

Jensen, P. D. O. (2009). A learning perspective on the offshoring of advanced services. Journal of International Management, 15(2), 181-193.

Jensen, P. D. O. (2012). A passage to India: a dual case study of activities, processes and resources in offshore outsourcing of advanced services. Journal of World Business, 47(2), 311-326.

Jensen, P. D. O., Larsen, M. M., \& Pedersen, T. (2013). The organizational design of offshoring: taking stock and moving forward. Journal of International Management, 19(4), 315-323.

Jensen, P. D. O., \& Pedersen, T. (2011). The economic geography of offshoring: the fit between activities and local context. Journal of Management Studies, 48(2), 352-372.

Jensen, P. D. O., \& Petersen, B. (2013). Build-operate-transfer outsourcing contracts in services-boon or bane to emerging market vendor firms? Journal of International Management, 19(3), 220-231.

Johanson, J., \& Vahlne, J. E. (1977). The internationalization process of the firm: a model of knowledge development and increasing foreign market commitments. Journal of International Business Studies, 8(1), 23-32.

Judge, T. A., Cable, D. M., Colbert, A. E., \& Rynes, S. (2007). What causes a management article to be cited-article, author, or journal? Academy of Management Journal, 50(3), 491-506. 
Kedia, B. L., \& Lahiri, S. (2007). International outsourcing of services: a partnership model. Journal of International Management, 13(1), 22-37.

Kedia, B. L., \& Mukherjee, D. (2009). Understanding offshoring: a research framework based on disintegration, location and externalization advantages. Journal of World Business, 44(3), 250-261.

Kenney, M., Massini, S., \& Murtha, T. P. (2009). Offshoring administrative and technical work: new fields for understanding the global enterprise. Journal of International Business Studies, 40(6), 887-900.

King, W. R., \& Torkzadeh, G. (2008). Information systems offshoring: research status and issues. MIS Quarterly, 32(2), 205-225.

Kotabe, M. (1989). "Hollowing-out" of U.S. multinationals and their global competitiveness-an intrafirm perspective. Journal of Business Research, 19(1), 1-15.

Kotabe, M., Mol, M. J., \& Ketkar, S. (2008). An evolutionary stage model of outsourcing and competence destruction: a triad comparison of the consumer electronics industry. Management International Review, 48(1), 65-93.

Kotabe, M., \& Mudambi, R. (2009). Global sourcing and value creation: opportunities and challenges. Journal of International Management, 15(2), 121-125.

Kothari, T., \& Lahiri, S. (2012). Yesterday, today and tomorrow: an overview of research publications in the Journal of International Management. Journal of International Management, 18(1), 102-110.

Kotlarsky, J., Scarbrough, H., \& Oshri, I. (2014). Coordinating expertise across knowledge boundaries in offshore-outsourcing projects: the role of codification. MIS Quarterly, 38(2), 607-627.

Kshetri, N. (2007). Institutional factors affecting offshore business process and information technology outsourcing. Journal of International Management, 13(1), 38-56.

Kshetri, N., \& Dholakia, N. (2009). Professional and trade associations in a nascent and formative sector of a developing economy: a case study of the NASSCOM effect on the Indian offshoring industry. Journal of International Management, 15(2), 225-239.

Kumar, K., van Fenema, P. C., \& von Glinow, M. A. (2009). Offshoring and the global distribution of work: implications for task interdependence theory and practice. Journal of International Business Studies, 40(4), 642-667.

Kundu, S. K., \& Merchant, H. (2008). Service multinationals: their past, present, and future. Management International Review, 48(4), 371-377.

Lacity, M. C., Khan, S., Yan, A. H., \& Willcocks, L. P. (2010). A review of the IT outsourcing empirical literature and future research directions. Journal of Information Technology, 25(4), 395-433.

Lacity, M. C., Solomon, S., Yan, A. H., \& Willcocks, L. P. (2011). Business process outsourcing studies: a critical review and research directions. Journal of Information Technology, 26(4), 221-258.

Lahiri, S., \& Kedia, B. L. (2009). The effects of internal resources and partnership quality on firm performance: an examination of Indian BPO providers. Journal of International Management, 15(2), 209-224.

Lahiri, S., \& Kedia, B. L. (2011). Co-evolution of institutional and organizational factors in explaining offshore outsourcing. International Business Review, 20(3), 252-263.

Lahiri, S., Kedia, B. L., \& Mukherjee, D. (2012). The impact of management capability on the resourceperformance linkage: examining Indian outsourcing providers. Journal of World Business, 47(1), $145-155$.

Lahiri, S., \& Kumar, V. (2012). Ranking international business institutions and faculty members using research publication as the measure: update and extension of prior research. Management International Review, 52(3), 317-340.

Lampel, J., \& Bhalla, A. (2011). Living with offshoring: the impact of offshoring on the evolution of organizational configurations. Journal of World Business, 46(3), 346-358.

Larsen, M. M., Manning, S., \& Pedersen, T. (2013). Uncovering the hidden costs of offshoring: the interplay of complexity, organizational design, and experience. Strategic Management Journal, 34(5), 533-552.

Levina, N., \& Vaast, E. (2008). Innovating or doing as told? Status differences and overlapping boundaries in offshore collaboration. MIS Quarterly, 32(2), 307-332.

Levy, D. L. (2005). Offshoring in the new global political economy. Journal of Management Studies, 42(3), 685-693.

Lewin, A. Y., Long, C. P., \& Carroll, T. N. (1999). The coevolution of new organizational forms. Organization Science, 10(5), 535-550.

Lewin, A. Y., Massini, S., \& Peeters, C. (2009). Why are companies offshoring innovation? The emerging global race for talent. Journal of International Business Studies, 40(6), 901-925. 
Lewin, A. Y., \& Peeters, C. (2006). Offshoring work: business hype or the onset of fundamental transformation? Long Range Planning, 39(3), 221-239.

Lewin, A. Y., \& Volberda, H. W. (1999). Prolegomena on coevolution: a framework for research on strategy and new organizational forms. Organization Science, 10(5), 519-534.

Lewin, A. Y., \& Volberda, H. W. (2011). Co-evolution of global sourcing: the need to understand the underlying mechanisms of firm-decisions to offshore. International Business Review, 20(3), 241-251.

Lewin, A. Y., \& Zhong, X. (2013). The evolving diaspora of talent: a perspective on trends and implications for sourcing science and engineering work. Journal of International Management, 19(1), 6-13.

Liesch, P. W., Buckley, P. J., Simonin, B. L., \& Knight, G. (2012). Organizing the modern firm in the worldwide market for market transactions. Management International Review, 52(1), 3-21.

Liu, R., Feils, D. J., \& Scholnick, B. (2011). Why are different services outsourced to different countries? Journal of International Business Studies, 42(4), 558-571.

Luo, Y. D., Wang, S. L., Jayaraman, V., \& Zheng, Q. Q. (2013). Governing business process offshoring: properties, processes, and preferred modes. Journal of World Business, 48(3), 407-419.

Luo, Y. D., Wang, S. L., Zheng, Q., \& Jayaraman, V. (2012). Task attributes and process integration in business process offshoring: a perspective of service providers from India and China. Journal of International Business Studies, 43(5), 498-524.

Manning, S. (2013). New Silicon Valleys or a new species? Commoditization of knowledge work and the rise of knowledge services clusters. Research Policy, 42(2), 379-390.

Manning, S. (2014). Mitigate, tolerate or relocate? Offshoring challenges, strategic imperatives and resource constraints. Journal of World Business, 49(4), 522-535.

Manning, S., Lewin, A. Y., \& Schuerch, M. (2011). The stability of offshore outsourcing relationships. Management International Review, 51(3), 381-406.

Manning, S., Massini, S., \& Lewin, A. Y. (2008). A dynamic perspective on next-generation offshoring: the global sourcing of science and engineering talent. Academy of Management Perspectives, 22(3), 35-54.

Manning, S., Ricart, J. E., Rosatti Rique, M. S., \& Lewin, A. Y. (2010). From blind spots to hotspots: how knowledge services clusters develop and attract foreign investment. Journal of International Management, 16(4), 369-382.

Mariotti, S., Piscitello, L., \& Elia, S. (2010). Spatial agglomeration of multinational enterprises: the role of information externalities and knowledge spillovers. Journal of Economic Geography, 10(4), 519-538.

Martínez-Noya, A., \& García-Canal, E. (2011). Technological capabilities and the decision to outsource/ outsource offshore R\&D services. International Business Review, 20(3), 264-277.

Martínez-Noya, A., García-Canal, E., \& Guillén, M. F. (2012). International R\&D service outsourcing by technology-intensive firms: whether and where? Journal of International Management, 18(1), 18-37.

Maskell, P., Pedersen, T., Petersen, B., \& Dick-Nielsen, J. (2007). Learning paths to offshore outsourcing: from cost reduction to knowledge seeking. Industry and Innovation, 14(3), 239-257.

Mason, K. J., \& Leek, S. (2008). Learning to build a supply network: an exploration of dynamic business models. Journal of Management Studies, 45(4), 774-799.

Massini, S., Perm-Ajchariyawong, N., \& Lewin, A. Y. (2010). Role of corporate-wide offshoring strategy on offshoring drivers, risks and performance. Industry and Innovation, 17(4), 337-371.

Mayer, K. J., \& Salomon, R. M. (2006). Capabilities, contractual hazards, and governance: integrating resource-based and transaction cost perspectives. Academy of Management Journal, 49(5), 942-959.

Mudambi, R., \& Venzin, M. (2010). The strategic nexus of offshoring and outsourcing decisions. Journal of Management Studies, 47(8), 1510-1533.

Mukherjee, D., Gaur, A. S., \& Datta, A. (2013). Creating value through offshore outsourcing: an integrative framework. Journal of International Management, 19(4), 377-389.

Murray, J. Y., \& Kotabe, M. (1999). Sourcing strategies of US service companies: a modified transactioncost analysis. Strategic Management Journal, 20(9), 791-809.

Nachum, L., \& Zaheer, S. (2005). The persistence of distance? The impact of technology on MNE motivations for foreign investment. Strategic Management Journal, 26(8), 747-767.

Narayanan, S., Balasubramanian, S., \& Swaminathan, J. M. (2009). A matter of balance: specialization, task variety, and individual learning in a software maintenance environment. Management Science, 55(11), 1861-1876. 
NASSCOM, \& McKinsey (2009). Perspective 2020: transform business, transform India. New Delhi: NASSCOM.

Nieto, M. J., \& Rodríguez, A. (2011). Offshoring of R\&D: looking abroad to improve innovation performance. Journal of International Business Studies, 42(3), 345-361.

Oshri, I., van Fenema, P., \& Kotlarsky, J. (2008). Knowledge transfer in globally distributed teams: the role of transactive memory. Information Systems Journal, 18(6), 593-616.

Parkhe, A. (2007). International outsourcing of services: introduction to the special issue. Journal of International Management, 13(1), 3-6.

Peeters, C., Massini, S., \& Lewin, A. Y. (2014). Sources of variation in the efficiency of adopting management innovation: the role of absorptive capacity routines, managerial attention and organizational legitimacy. Organization Studies, 35(9), 1343-1371.

Pereira, V., \& Anderson, V. (2012). A longitudinal examination of HRM in a human resources offshoring (HRO) organization operating from India. Journal of World Business, 47(2), 223-231.

Pisani, N. (2009). International management research: investigating its recent diffusion in top management journals. Journal of Management, 35(2), 199-218.

Podsakoff, P. M., Mackenzie, S. B., Bachrach, D. G., \& Podsakoff, N. P. (2005). The influence of management journals in the 1980s and 1990s. Strategic Management Journal, 26(5), 473-488.

Porter, M. E., \& Rivkin, J. W. (2012). Choosing the United States. Harvard Business Review, 90(3), 80-93.

Raman, R., Chadee, D., Roxas, B., \& Michailova, S. (2013). Effects of partnership quality, talent management, and global mindset on performance of offshore IT service providers in India. Journal of International Management, 19(4), 333-346.

Rilla, N., \& Squicciarini, M. (2011). R\&D (re)location and offshore outsourcing: a management perspective. International Journal of Management Reviews, 13(4), 393-413.

Roza, M., Van den Bosch, F. A. J., \& Volberda, H. W. (2011). Offshoring strategy: motives, functions, locations, and governance modes of small, medium-sized and large firms. International Business Review, 20(3), 314-323.

Schmeisser, B. (2013). A systematic review of literature on offshoring of value chain activities. Journal of International Management, 19(4), 390-406.

Sidhu, J. S., \& Volberda, H. W. (2011). Coordination of globally distributed teams: a co-evolution perspective on offshoring. International Business Review, 20(3), 278-290.

Soderberg, A. M., Krishna, S., \& Bjorn, P. (2013). Global software development: commitment, trust and cultural sensitivity in strategic partnerships. Journal of International Management, 19(4), 347-361.

Srikanth, K., \& Puranam, P. (2011). Integrating distributed work: comparing task design, communication, and tacit coordination mechanisms. Strategic Management Journal, 32(8), 849-875.

Srikanth, K., \& Puranam, P. (2014). The firm as a coordination system: evidence from software services offshoring. Organization Science, 25(4), 1253-1271.

Tambe, P., \& Hitt, L. M. (2012). Now IT's personal: offshoring and the shifting skill composition of the US information technology workforce. Management Science, 58(4), 678-695.

Tranfield, D., Denyer, D., \& Smart, P. (2003). Towards a methodology for developing evidence-informed management knowledge by means of systematic review. British Journal of Management, 14(3), 207-222.

UNCTAD. (2004). World Investment Report. New York: United Nations.

Vivek, S. D., Richey, R. G, Jr, \& Dalela, V. (2009). A longitudinal examination of partnership governance in offshoring: a moving target. Journal of World Business, 44(1), 16-30.

Vlaar, P. W. L., van Fenema, P. C., \& Tiwari, V. (2008). Cocreating understanding and value in distributed work: how members of onsite and offshore vendor teams give, make, demand, and break sense. MIS Quarterly, 32(2), 227-255.

Walsh, G., Gouthier, M., Gremler, D. D., \& Brach, S. (2012). What the eye does not see, the mind cannot reject: can call center location explain differences in customer evaluations? International Business Review, 21(5), 957-967.

Werner, S. (2002). Recent developments in international management research: a review of 20 top management journals. Journal of Management, 28(3), 277-305.

Williams, C. (2011). Client-vendor knowledge transfer in IS offshore outsourcing: insights from a survey of Indian software engineers. Information Systems Journal, 21(4), 335-356.

Williamson, O. E. (1981). The economics of organization: the transaction cost approach. American Journal of Sociology, 87(3), 548-577. 
Youngdahl, W., \& Ramaswamy, K. (2008). Offshoring knowledge and service work: a conceptual model and research agenda. Journal of Operations Management, 26(2), 212-221.

Zaheer, S. (1995). Overcoming the liability of foreignness. Academy of Management Journal, 38(2), 341-363.

Zaheer, S., Lamin, A., \& Subramani, M. (2009). Cluster capabilities or ethnic ties? Location choice by foreign and domestic entrants in the services offshoring industry in India. Journal of International Business Studies, 40(6), 944-968.

Zaheer, S., \& Manrakhan, S. (2001). Concentration and dispersion in global industries: remote electronic access and the location of economic activities. Journal of International Business Studies, 32(4), $667-686$.

Zimmermann, A., \& Ravishankar, M. N. (2014). Knowledge transfer in IT offshoring relationships: the roles of social capital, efficacy and outcome expectations. Information Systems Journal, 24(2), 167-202. 